\title{
Tetrathiomolybdatorhodium(I) Complexes
}

\section{Exhibiting Interesting Properties of Electronic}

\author{
Nature
}

Nikoletta Xamonaki, ${ }^{\uparrow}$ Anastasios Asimakopoulos, ${ }^{\uparrow}$ Anastasios Balafas ${ }^{\uparrow}$, Marilena Dasenaki, $\uparrow$

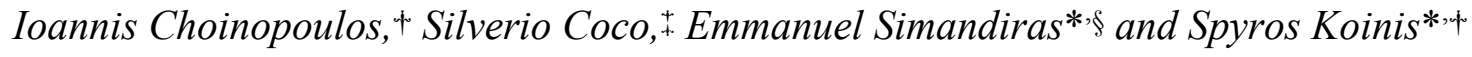

${ }^{\dagger}$ Faculty of Chemistry, National and Kapodistrian University of Athens, 15771 Athens, Greece, ${ }^{\ddagger}$ IU/CINQUIMA, Química Inorgánica, Facultad de Ciencias, Universitad de Valladolid, 47071 Valladolid, Spain, ${ }^{\S}$ Theoretical and Physical Chemistry Institute, National Hellenic Research Foundation, 11635 Athens, Greece

KEYWORDS. rhodium; tetrathiomolybdate; DFT; electronic communication; electronic spectroscopy; ligand electronic parameter; ${ }^{31} \mathrm{P}$ NMR; QALE. 
ABSTRACT. The synthesis and characterization of the tetrathiomolybdatorhodium(I) monoanionic complexes $\left[\mathrm{L}_{2} \mathrm{Rh}(\mu-\mathrm{S})_{2} \mathrm{MoS}_{2}\right]^{-}\left(\mathrm{L}=\mathrm{CO}\right.$ 3, $\mathrm{P}(\mathrm{OPh})_{3}$ 4, $\mathrm{P}(\mathrm{O}-o-\mathrm{Tol})_{3}$ 5, $\mathrm{P}(\mathrm{OMe})_{3}$ 6, $\mathrm{P}(\mathrm{OEt})_{3}$ 7, $\mathrm{P}(\mathrm{O}-i-\mathrm{Pr})_{3}$ 8; $\mathrm{L}_{2}=\mathrm{COD} 2$, cis-dppen 9, dppe 10, dppb 11), is presented. The complex $2\left(\mathrm{NEt}_{4}{ }^{+}\right.$salt) was characterized by X-ray diffraction analysis. The detailed DFT study of the electronic structure of $\mathbf{2 , 3}, \mathbf{4}, \mathbf{6}, 7$ and $\mathbf{8}$ has revealed the existence of extended electron delocalization over the four-membered $\mathrm{Rh}(\mu-\mathrm{S})_{2}$ Mo ring and hence the possibility of electronic communication between the metal centers. The electronic spectra were studied with TDDFT calculations and the main absorption band in the visible was assigned to $r(\mathrm{Rh} \rightarrow \mathrm{Mo})$ electron transfer transition, which is actually a HOMO-LUMO transition. The $v(\mathrm{Rh} \rightarrow \mathrm{Mo})$ transition was found to correlate linearly both with Tolman's electronic parameter of the phosphite ligands and the calculated HOMO-LUMO gap of the complexes, rendering it a well defined ligand electronic parameter, which describes the net donating ability of monodentate and bidentate ligands $(\mathrm{CO}$, COD, phosphites, diphosphines). The study of the variation of $\Delta \delta\left({ }^{31} \mathrm{P}\right)$ and ${ }^{1} J(\mathrm{Rh}-\mathrm{P})$ of the phosphite complexes with respect to the QALE model electronic parameters $\chi_{\mathrm{d}}, \pi_{\mathrm{p}}$ and $E_{\mathrm{ar}}$ has succeeded in the assessment of the $\sigma$ and $\pi$ effects on these NMR spectral parameters. 


\section{INTRODUCTION}

The Group 6 tetrathiometallate dianions, $\mathrm{MoS}_{4}{ }^{2-}$ and $\mathrm{WS}_{4}{ }^{2-}$, display unique ligand properties and have been widely used as ligands for transition metals for the synthesis of multimetallic complexes and organometallic compounds. ${ }^{1}$ Interest in these compounds has expanded rapidly mainly because of their structural relation to the active sites of the nitrogen fixing enzymes, ${ }^{2}$ for the synthesis of industrial hydrodesulfurization catalysts, ${ }^{3}$ their potential applications as nonlinear optical (NLO) materials ${ }^{4}$, as precursors for new inorganic solids with unusual stoichiometries, ${ }^{1 \mathrm{~h}, 5}$ their activity in homogeneous catalysis ${ }^{6}$ and their applications in anti-tumor (antiangiogenic) therapy. ${ }^{7}$

Beginning in the early 1970s Müller and his co-workers pioneered the systematic study of transition metal complexes derived from tetrathiometallates. ${ }^{1 \mathrm{~b}}$ In 1986 Rauchfuss, Rheingold et al. first reported that $\mathrm{MoS}_{4}{ }^{2-}$ and $\mathrm{WS}_{4}{ }^{2-}$ can also function as ligands for low-valent organometallic compounds, which in turn are reactive toward $\pi$-acid ligands. ${ }^{8}$

In most cases the tetrathiometallates, $\mathrm{MS}_{4}{ }^{2-}$, function as either terminal (I, III) or bridging (II) chelating ligands (Scheme 1). The dinuclear structure I can be considered as the parent structure of II and III.

Scheme 1 Usual modes of coordination of tetrathiometallato $\left(\mathrm{MS}_{4}{ }^{2-}\right)$ ligands.

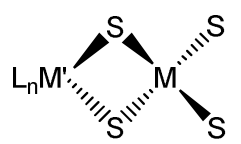

I

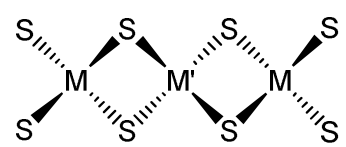

IIIa

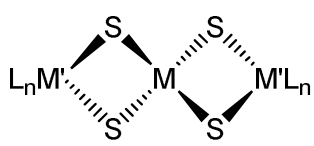

II

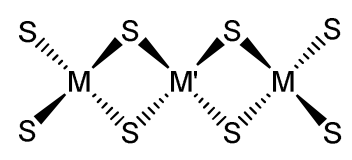

IIIb 
There are far more transition metal complexes with $\mathrm{WS}_{4}{ }^{2-}$ than with $\mathrm{MoS}_{4}{ }^{2-}$. This is due to the fact that the salts of $\mathrm{WS}_{4}{ }^{2-}$ are more resistant to hydrolysis (conversion to oxo-species) than the corresponding $\mathrm{MoS}_{4}{ }^{2-}$ compounds. ${ }^{9}$ Structurally characterized dinuclear complexes $\mathrm{L}_{\mathrm{n}} \mathrm{M}^{\prime}\left(\mathrm{MoS}_{4}\right)$ have been reported for $\mathrm{M}^{\prime}=\mathrm{Mo}^{0}, \mathrm{Fe}^{\mathrm{II}}, \mathrm{Pd}^{\mathrm{II}}, \mathrm{Cu}^{\mathrm{I}}$ and $\mathrm{Ag}^{\mathrm{I}} \cdot{ }^{10}$

Many tetrathiometallato complexes have been described as having unusual electronic properties on the ground of spectroscopic (UV-Vis, IR, Raman, NMR) and electrochemical (CV) measurements, chemical reactivity and X-ray solid state structures. ${ }^{1 b, 10 a, 10 b, 11}$ The origin of these properties has been attributed to the ability of the $\mathrm{MS}_{4}{ }^{2-}$ anions to facilitate the delocalization of electrons and to metal-metal bonding interactions, ${ }^{12}$ resulting among else in the long range electronic communication between the metal centers. The electronic structure of the free tetrathiometallates and their complexes has been the subject of several theoretical studies, ${ }^{13}$ but the unraveling of the origin of their peculiar properties is still an open issue.

Both $\operatorname{Rh}^{\mathrm{I}}\left(\mathrm{d}^{8}\right)^{5,8,11 \mathrm{c}, 14}$ and $\mathrm{Rh}^{\mathrm{III}}\left(\mathrm{d}^{6}\right)^{5,15}$ tetrathiometallato complexes, mainly with $\mathrm{WS}_{4}{ }^{2-}$, have been reported. This could be of interest from the point of view of homogeneous catalysis, since the interconversions $\mathrm{Rh}^{\mathrm{I}} \rightarrow \mathrm{Rh}^{\mathrm{III}}$ and $\mathrm{Rh}^{\mathrm{III}} \rightarrow \mathrm{Rh}^{\mathrm{I}}$ through oxidative addition and reductive elimination reactions, respectively, are crucial steps of the catalytic cycle in most rhodium catalyzed reactions. ${ }^{16}$ There is only one dinuclear $\mathrm{Rh}^{\mathrm{I}}$ complex reported so far, $\left(\mathrm{PPh}_{4}\right)\left[(\mathrm{COD}) \mathrm{Rh}(\mu-\mathrm{S})_{2} \mathrm{WS}_{2}\right],{ }^{8}$ while several trinuclear $\left(\mathrm{Rh}^{\mathrm{I}} \mathrm{Mo}^{\mathrm{VI}} \mathrm{Rh}^{\mathrm{I}}, \mathrm{Rh}^{\mathrm{I}} \mathrm{W}^{\mathrm{VI}} \mathrm{Rh}^{\mathrm{I}}\right.$ and $\left.\mathrm{Rh}^{\mathrm{I}} \mathrm{W}^{\mathrm{VI}} \mathrm{W}^{0}\right)$ complexes have been reported (SI.1 in Supporting Information). The stabilization of the lowvalent $\mathrm{Rh}^{\mathrm{I}}$ complexes is accomplished mainly through the coordination of strong $\pi$-acceptor (also weak $\sigma$-donor) ligands (COD, NBD, $\mathrm{CO}, t$-BuNC). In contrast, the stabilization of the $\mathrm{Rh}^{\mathrm{III}}$ tetrathiotungstato complexes is accomplished mainly through the coordination of $\sigma$-donor ligands (Cp, $\mathrm{Cp}^{*}, \mathrm{PMe}_{3}, \mathrm{Cl}($ also a $\pi$-donor $)$ ). 
There seems to be one more difference between the $\mathrm{Rh}^{\mathrm{I}}$ and $\mathrm{Rh}^{\mathrm{III}}$ species, namely the geometry of the $\mathrm{Rh}(\mu-\mathrm{S})_{2} \mathrm{~W}$ four-membered ring. Although the number of the structurally characterized rhodium tetrathiometallato complexes is limited, the existing data show that the ring in $\mathrm{Rh}^{\mathrm{I}}$ complexes is perfectly planar, while in $\mathrm{Rh}^{\mathrm{III}}$ complexes possesses a butterfly arrangement. $^{8,11 \mathrm{c}, 14,15 \mathrm{a}-\mathrm{d}}$

The present work concerns the synthesis, structure and spectroscopic properties of dinuclear tetrhathiomolybdatorhodium(I) (TTMR) complexes with strong $\pi$-acceptor ligands (COD, CO, commercially available phosphites) and $\sigma$-donor chelating diphosphines. The electronic structure and the electronic spectra of these complexes were studied with DFT calculations and the electronic communication between the metal atoms is described in detail. Finally, interesting correlations of the experimental UV-Vis and ${ }^{31} \mathrm{P}$ NMR spectroscopic parameters with respect to widely used ligand electronic parameters are presented and discussed. 


\section{RESULTS AND DISCUSSION}

Syntheses. The relatively unstable trinuclear complex $\left[\left\{\left(\eta^{4}-\mathrm{COD}\right) \mathrm{Rh}\right\}_{2}\left(\mu-\mathrm{MoS}_{4}\right)\right]$

$(\mathrm{COD}=1,5-\mathrm{Cyclooctadiene}),{ }^{8,11 \mathrm{~d}}$ which is formed by reacting $[\mathrm{RhCl}(\mathrm{COD})]_{2}$ with $\mathrm{MoS}_{4}{ }^{2-}$ (eq. I), was found to react further with $\mathrm{MoS}_{4}{ }^{2-}$ yielding the stable dinuclear monoanionic complex $\left[\left(\eta^{4}-\right.\right.$ $\left.\mathrm{COD}) \mathrm{Rh}(\mu-\mathrm{S})_{2} \mathrm{MoS}_{2}\right]^{-}$(2) (eq. II):

$$
\begin{aligned}
& {[\mathrm{RhCl}(\mathrm{COD})]_{2}+\mathrm{MoS}_{4}{ }^{2-} \rightarrow\left[\{(\mathrm{COD}) \mathrm{Rh}\}_{2}\left(\mathrm{MoS}_{4}\right)\right]+2 \mathrm{Cl}^{-}} \\
& {\left[\{(\mathrm{COD}) \mathrm{Rh}\}_{2}\left(\mathrm{MoS}_{4}\right)\right]+\mathrm{MoS}_{4}{ }^{2-} \rightarrow 2\left[(\mathrm{COD}) \mathrm{Rh}\left(\mathrm{MoS}_{4}\right)\right]^{-}}
\end{aligned}
$$

The synthesis of $\mathbf{2}$ seems to be easily accomplished in acetone. Complex $\mathbf{1}$ (bright violet) is prepared, followed by the immediate addition of 1 eq of $\mathrm{MoS}_{4}{ }^{2-}$, which results in the formation of an apparently clear pink solution (pathway A, Scheme 2). The measurement of the UV-Vis spectrum of the reaction mixture showed repeatedly an unexpected small drift of the baseline, which could be attributed to the presence of a finely divided solid. This was confirmed, by the deposition of a small quantity of a dark colored solid upon standing of the reaction mixture in the flask for ca. 1 hour.

The synthesis of 2 , in one step, by reacting $[\mathrm{RhCl}(\mathrm{COD})]_{2}$ and $\mathrm{MoS}_{4}{ }^{2-}$ in $1 \div 2$ molar ratio in acetone, also gave the same result. It was our belief that the by-products formed should be a mixture of decomposition products of the complex $\mathbf{1 .}$

Since the tetrathiomolybdate starting materials used, $\left(\mathrm{NEt}_{4}\right)_{2}\left(\mathrm{MoS}_{4}\right)$ and $\left(\mathrm{PPh}_{4}\right)_{2}(\mathrm{MoS} 4)$, are only slightly soluble in acetone, we have tried to perform the synthesis differently. First, we dissolved the tetrathiomolybdate salt in acetonitrile and $[\mathrm{RhCl}(\mathrm{COD})]_{2}$ in acetone separately. Then, we added dropwise one solution to the other. The solution which is slowly added to the other is of the outmost importance as described hereunder. The synthesis of $\mathbf{2}$ is an important 
example where the experimental procedure strictly dictates the product and byproducts of the reaction. In this case, the rate and sequence of mixing the reactants is of outmost importance. ${ }^{17}$ Upon the slow addition of the solution of tetrathiomolybdate to the solution of rhodium the color of the reaction mixture first turned reddish-violet, indicative of the formation of $\mathbf{1}$ (violet) and the presence of free $\mathrm{MoS}_{4}{ }^{2-}$ (red), which gradually turned pink (pathway $\mathbf{C}$, Scheme 2). The formation of a small quantity of the dark colored solid byproduct renders this procedure inadequate.

Finally, the quantitative preparation of $\mathbf{2}$ was accomplished by the slow addition of the solution of rhodium to the solution of the tetrathiomolybdate which resulted in the direct change of the color of the solution to pink, without the formation of any by-products (pathway $\mathbf{B}$, Scheme 2). It seems that following this pathway the intermediate unstable complex $\mathbf{1}$ once formed it reacts fast with the excess $\mathrm{MoS}_{4}{ }^{2-}$ present, so that the concentration of $\mathbf{1}$ in the reacting system is practically negligible. The quantitative output of the reaction was confirmed by UV-Vis (complete disappearance of the $472 \mathrm{~nm}\left(\varepsilon_{\max } 14,600\right)$ band of $\mathrm{MoS}_{4}{ }^{2-} 18$ and ESI-MS measurements of the reaction mixtures. Complex $\mathbf{2}$ is a versatile synthetic starting material for the preparation of many complexes (Scheme 3). 
Scheme 2. Summary of synthetic pathways leading to the formation of complex 2.

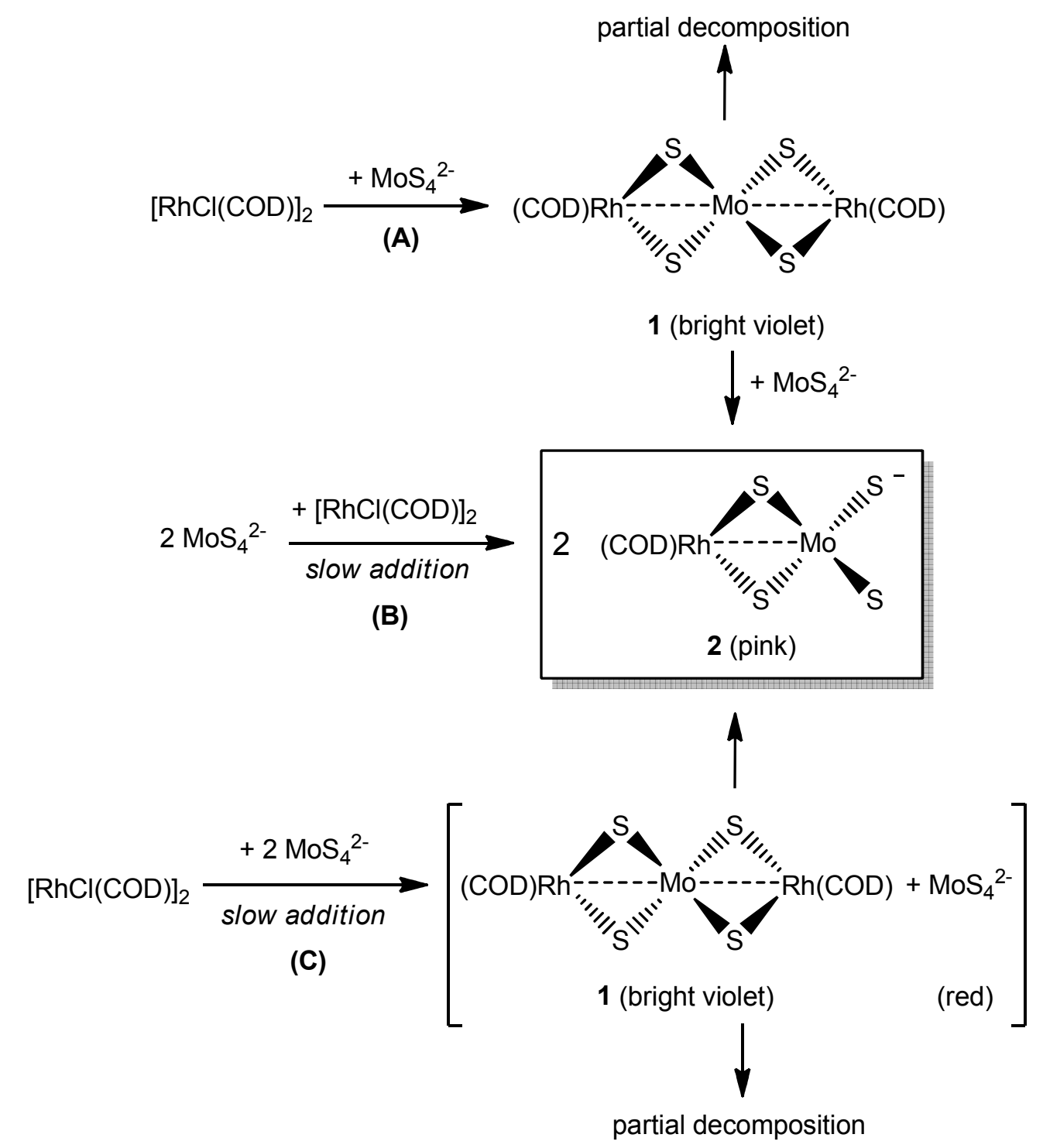

43

44

45

46

47

48

49

50

51

52

53

54

55

56

57

58

59 
Scheme 3. Some reactions of complex 2.
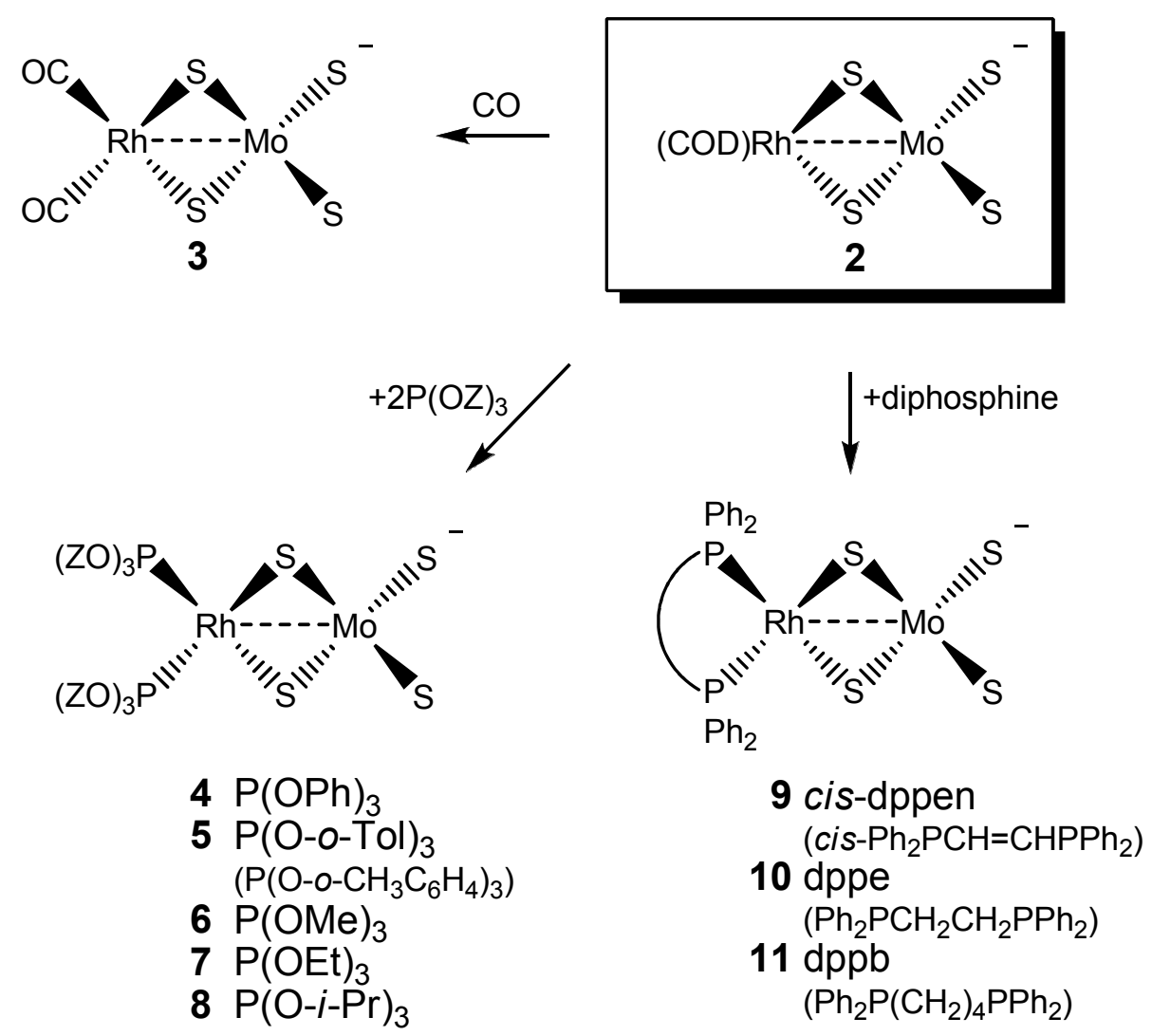

The complexes with trivalent phosphorus ligands (4-11) were formed quantitatively, as demonstrated by measuring the ${ }^{31} \mathrm{P}$ NMR spectra of the reaction mixtures, in which only the signal of the coordinated phosphorus ligand was observed. The composition of complexes 4-11 was proven by ESI-MS (SI.2 in Supporting Information).

Complex 2 did not react with the $\sigma$-donor $\mathrm{PPh}_{3}$ (even at 20-fold excess), while the respective trinuclear complex $\left[\left\{\left(\mathrm{PPh}_{3}\right)_{2} \mathrm{Rh}\right\}_{2}\left(\mu-\mathrm{MoS}_{4}\right)\right]$ can be readily prepared. ${ }^{11 \mathrm{c}}$ The formation of the complexes with the $\sigma$-donor chelating diphosphines (9-11) should thus be attributed to the additional stabilization arising from the formation of the chelate ring. 
The dicarbonyl species $\mathbf{3}$, was formed in situ by bubbling cautiously and at low rate CO through a solution of $\mathbf{2}$ until the red orange solution turned into yellow. Excess CO causes the change of the color of the solution into dark golden, which was found to be an indication of the collapse of the dicarbonyl cluster. The structure of $\mathbf{3}$ was assigned on the basis of UV-Vis and IR spectra. The UV-Vis spectrum is characteristic of TTMR species, vide infra, while the IR spectrum $\left(\mathrm{CH}_{2} \mathrm{Cl}_{2}\right)$ showed in the $v(\mathrm{CO})$ region two strong bands at 2064 and $2012 \mathrm{~cm}^{-1}$, assigned to $v_{\mathrm{sym}}(\mathrm{C}-\mathrm{O})$ and $v_{\mathrm{asym}}(\mathrm{C}-\mathrm{O})$ respectively. The $v(\mathrm{C}-\mathrm{O})$ bands are comparable to those observed for other cis-dicarbonyl rhodium(I) species e.g. cis- $\left[\mathrm{RhX}_{2}(\mathrm{CO})_{2}\right]^{-}\left(\mathrm{Nujol} ; \mathrm{NBu}_{4}{ }^{+} \mathrm{salts}\right.$ : $\mathrm{X}=\mathrm{Cl} 2058,1974 \mathrm{~cm}^{-1} ; \mathrm{X}=\mathrm{Br} 2062,1985 \mathrm{~cm}^{-1} ; \mathrm{X}=\mathrm{I} 2052,1985 \mathrm{~cm}^{-1}$ and $\left[\mathrm{Rh}(\mathrm{acac})(\mathrm{CO})_{2}\right]$ $\left(\mathrm{CHCl}_{3}\right) 2085.0,2014.5 \mathrm{~cm}^{-1} \cdot{ }^{19}$

\section{X-ray Structure of $2\left(\mathrm{NEt}_{4}{ }^{+}\right.$salt).}

Single crystals of $2\left(\mathrm{NEt}_{4}{ }^{+}\right.$salt) suitable for X-ray diffraction measurements, were obtained by slow diffusion of $n$-hexane into a solution of the complex in dichloromethane. The molecular structure of 2 and numbering scheme is shown in Figure 1. (Crystal data and X-ray data collection and refinement are given in SI.3 in Supporting Information). A listing of important bond distances and bond angles is given in Table 1.

The main characteristics of the molecular structure of $\mathbf{2}$ are (a) the planarity of the $\operatorname{Rh}(\mu$ S) ${ }_{2}$ Mo ring, and (b) the short Rh-Mo distance of $2.8787(12) \AA$, which is indicative of metalmetal bonding interaction. The Rh-S distances and the Rh-S-Mo angles of 2 are comparable with the Rh-S distances and the Rh-S-W angles of $\left[\left\{\left(\eta^{4}-\mathrm{COD}\right) \mathrm{Rh}\right\}_{2}\left(\mu-\mathrm{WS}_{4}\right)\right]$. $^{8,11 \mathrm{a}}$ 


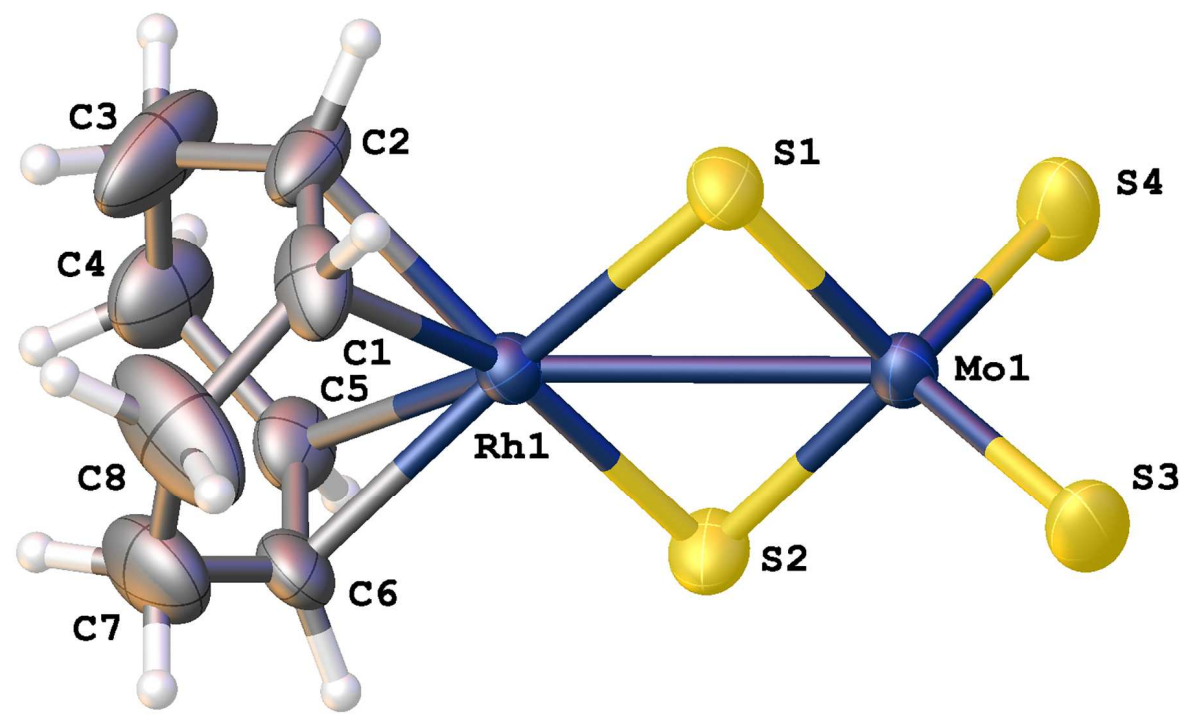

Figure 1. Molecular structure of 2 . Thermal ellipsoids are at 50\% probability.

Table 1. Selected Bond Lengths $(\AA)$ and Bond Angles (deg) of 2.

$\begin{array}{llll}\text { Rh1-S1 } & 2.3291(15) & \text { C1-Rh1-C2 } & 37.60(18) \\ \text { Rh1-S2 } & 2.3190(17) & \text { C5-Rh1-C6 } & 37.32(16) \\ \text { Mo1-S1 } & 2.2287(17) & \text { S1-Rh1-S2 } & 98.70(4) \\ \text { Mo1-S2 } & 2.2309(15) & \text { Rh1-S2-Mo1 } & 78.47(4) \\ \text { Mo1-S3 } & 2.1721(17) & \text { S1-Mo1-S2 } & 104.52(4) \\ \text { Mo1-S4 } & 2.1454(17) & \text { Mo1-S1-Rh1 } & 78.30(3) \\ \text { Rh1-Mo1 } & 2.8788(12) & \text { S3-Mo1-S4 } & 110.12(5)\end{array}$

DFT Calculations. In order to gain insight into the electronic structure of the TTMR complexes, the structures of $\mathbf{2}, \mathbf{3}, \mathbf{4}, \mathbf{6}, \mathbf{7}$ and $\mathbf{8}$ were fully optimized using the B3LYP functional with DFT and a large triple zeta plus two polarization functions basis set (def2-TZVPP). 
Selected parameters of the calculated stable structures are presented in Table 2. In all cases the coordination of rhodium can be described as square planar and that of Mo as tetrahedral. The calculated Rh-Mo distances were in the range of $2.988 \pm 0.005 \AA$ and the $\mathrm{Rh}(\mu-\mathrm{S})_{2} \mathrm{Mo}$ rings were found to be perfectly planar, in close agreement with the respective features of the molecular structure of complex 2 and the aforementioned planarity of the ring for the $\mathrm{Rh}(\mathrm{I})$ tetrathiometallato complexes. (Optimized structures, bond lengths and bond angles are given in SI.4 in Supporting Information). The HOMO-LUMO energy gap was found to vary parallel to the $\pi$-acidity of the phosphites (as described by the Tolman's electronic parameter ${ }^{20}$ ), while the Rh-P bond lengths to vary antiparallel. The calculated $v(\mathrm{CO})$ vibrations of complex $\mathbf{3}, v_{\mathrm{sym}}(\mathrm{C}-\mathrm{O})$ $2097.5 \mathrm{~cm}^{-1}$ and $v_{\text {asym }}(\mathrm{C}-\mathrm{O}) 2042.2 \mathrm{~cm}^{-1}$, are in acceptable agreement with the experimental values.

Table 2. Selected computed parameters of the stable structures of complexes $2, \mathbf{3}, \mathbf{4}, \mathbf{6}, \mathbf{7}$ and $\mathbf{8}$ (def2TZVPP)

\begin{tabular}{|c|c|c|c|c|c|}
\hline Complex & $\begin{array}{l}\text { Rh-Mo } \\
(\AA)\end{array}$ & $\begin{array}{l}\text { Rh-P } \\
(\AA)\end{array}$ & $\begin{array}{l}\Delta E^{a} \\
(\mathrm{eV})\end{array}$ & $\begin{array}{l}Q(\mathrm{Rh})^{b} \\
\text { (a.u.) }\end{array}$ & $\begin{array}{l}Q(\mathrm{Mo})^{b} \\
\text { (a.u.) }\end{array}$ \\
\hline$\left[(\mathrm{CO})_{2} \mathrm{Rh}(\mu-\mathrm{S})_{2} \mathrm{MoS}_{2}\right]^{-}$ & 2.994 & - & 3.536 & +0.10 & +0.87 \\
\hline$\left[(\mathrm{COD}) \mathrm{Rh}(\mu-\mathrm{S})_{2} \mathrm{MoS}_{2}\right]^{-}$ & 2.990 & - & 3.524 & +0.02 & +0.86 \\
\hline$\left[\left((\mathrm{PhO})_{3} \mathrm{P}\right)_{2} \mathrm{Rh}(\mu-\mathrm{S})_{2} \mathrm{MoS}_{2}\right]^{-}$ & 2.987 & 2.206 & 3.429 & -0.08 & +0.65 \\
\hline$\left[\left((\mathrm{MeO})_{3} \mathrm{P}\right)_{2} \mathrm{Rh}(\mu-\mathrm{S})_{2} \mathrm{MoS}_{2}\right]^{-}$ & 2.983 & 2.207 & 3.368 & -0.27 & +0.76 \\
\hline$\left.\left[((\mathrm{EtO}))_{3} \mathrm{P}\right)_{2} \mathrm{Rh}(\mu-\mathrm{S})_{2} \mathrm{MoS}_{2}\right]^{-}$ & 2.988 & 2.212 & 3.363 & -0.27 & +0.73 \\
\hline$\left[\left((\mathrm{Pr}-i-\mathrm{O})_{3} \mathrm{P}\right)_{2} \mathrm{Rh}(\mu-\mathrm{S})_{2} \mathrm{MoS}_{2}\right]^{-}$ & 2.986 & 2.225 & 3.321 & -0.12 & +0.62 \\
\hline
\end{tabular}


The examination of the bonding MOs revealed the existence of extended electron delocalization over the four-membered $\mathrm{Rh}(\mu-\mathrm{S})_{2} \mathrm{Mo}$ ring, and hence the possibility of electronic communication between the metal centers. The most relevant of these bonding MOs are shown in Figure 2. These bonding features suggest that the electronic effects induced by the variation of the $\pi$-acceptor ligands could affect the electronic density on both metal atoms, as demonstrated by the variation of the computed Mulliken electric charges on $\mathrm{Rh}$ and Mo listed in Table 2 .

The Rh-Mo bonding is depicted by the lowest energy MOs shown in Figure 2, which arise from the mixing of the $\mathrm{S} p$ orbitals with the $\mathrm{d} \delta$ orbitals of Rh and Mo. Each one of these MOs represents a four-center two-electron bond, which includes $\mathrm{Rh}-\mathrm{Mo}, \mathrm{Rh}-\mathrm{S}_{\mathrm{br}}$, Mo- $\mathrm{S}_{\mathrm{br}}$ and $\mathrm{S}_{\mathrm{br}}-\mathrm{S}_{\mathrm{br}}$ bonding interactions. This type of mixing of the $\mathrm{S} p$ orbitals with the $\mathrm{d} \delta$ metal orbitals is not unprecedented and has been also suggested by Murillo et al. for the $\operatorname{Mo}^{\mathrm{II}}(\mu-\mathrm{SR})_{2} \mathrm{Mo}^{\mathrm{II}}$ fourmembered ring in $\left[\mathrm{Mo}_{2}(c i s-\mathrm{DAniF})_{2}\right]_{2}\left[\left(\mu-\mathrm{O}-\mathrm{S}_{2} \mathrm{C}_{6} \mathrm{H}_{4}\right)_{2}\right],{ }^{21}$ although in this case there is no metalmetal bonding interaction (Mo $\cdots$ Mo $3.724 \AA$ ).

The HOMO and the LUMO of the complexes are non-bonding MOs and are remarkably identical (SI.5 in Supporting Information). The HOMO possesses electron density on the Rh and the four S atoms and the LUMO on the Mo and the four S atoms. 


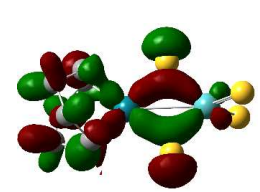

HOMO-16

$(-5.632 \mathrm{eV})$
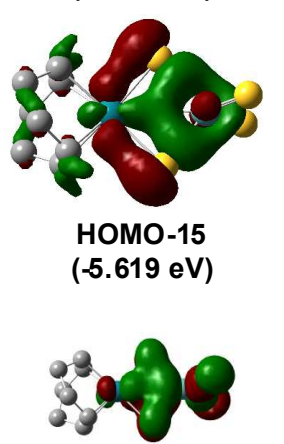

HOMO-14 $(-5.335 \mathrm{eV})$

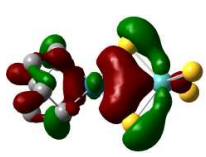

HOMO-17 $(-6.133 \mathrm{eV})$

2
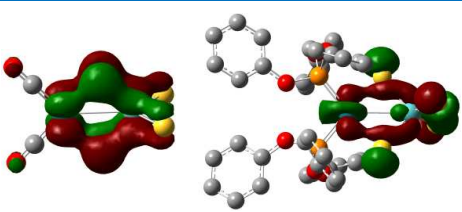

HOMO-21

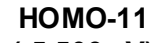

$(-5.509 \mathrm{eV})$

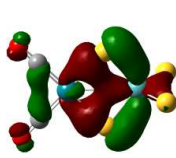

HOMO-13

$(-5.775 \mathrm{eV})$

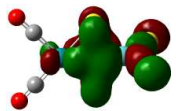

HOMO-14 $(-5.807 \mathrm{eV})$

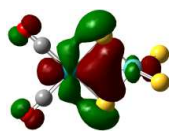

HOMO-15 $(-6.611 \mathrm{eV})$

3

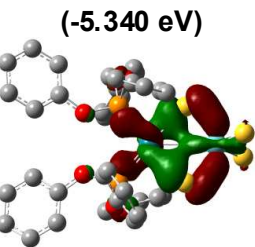

HOMO-25 $(-5.671 \mathrm{eV})$

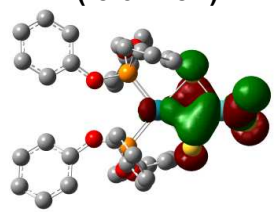

HOMO-26

$(-5.748 \mathrm{eV})$

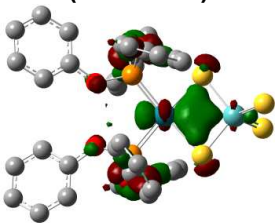

HOMO-29

$(-6.648 \mathrm{eV})$

4

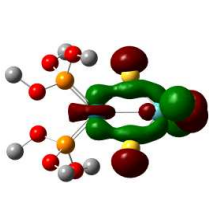

HOMO-6 $(-3.721 \mathrm{eV})$

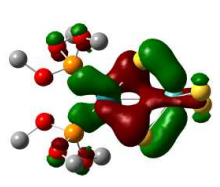

HOMO-13 $(-5.094 \mathrm{eV})$

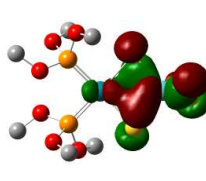

HOMO-14 $(-5.267 \mathrm{eV})$

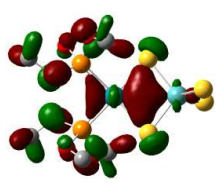

HOMO-21 $(-6.185 \mathrm{eV})$

6

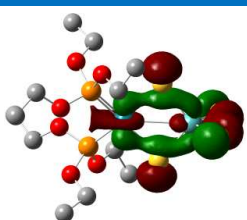

HOMO-6

$(-3.717 \mathrm{eV})$

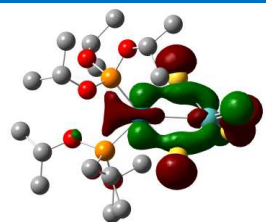

HOMO-6

$(-3.660 \mathrm{eV})$

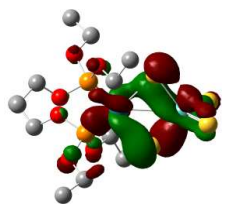

HOMO-13

(-5.074 eV)

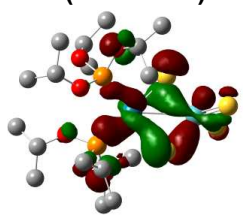

HOMO-12

(-4.998 eV)

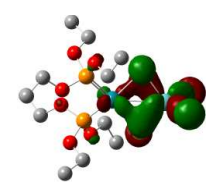

HOMO-14

$(-5.263 \mathrm{eV})$

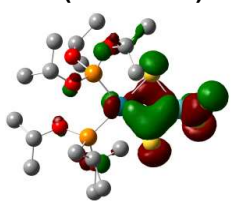

HOMO-14

$(-5.162 \mathrm{eV})$

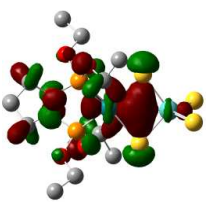

HOMO-21

$(-6.134 \mathrm{eV})$

7

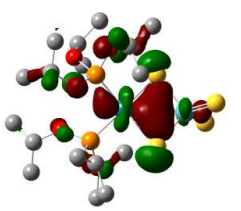

HOMO-21

$(-6.019 \mathrm{eV})$

8

Figure 2. Bonding features of the $\operatorname{Rh}(\mu-\mathrm{S})_{2}$ Mo ring for complexes $\mathbf{2}, \mathbf{3}, \mathbf{4 , 6}, \mathbf{7 , 8}$, isovalue $=0.04$. $(\mathrm{MOs}$ of related shapes arranged in the same row).

Electronic Spectroscopy. The electronic absorption spectra of all the TTMR complexes consist of a well resolved intense main band in the Vis region and two shoulders at lower wavelengths, Figure 3. This characteristic shape, exhibited by all complexes studied, implies that the electronic spectra can be used as a diagnostic criterion for the confirmation of the formation of the TTMR complexes. The predictability in the spectral patterns of the electronic spectra of 
tetrathiometalato complexes has been also noted previously by Coucouvanis et al. for the dinuclear $\mathrm{L}_{2} \mathrm{Fe}^{\mathrm{II}} \mathrm{S}_{2} \mathrm{MoS}_{2}$ complexes. ${ }^{10 \mathrm{~b}}$

As shown in Table 3, the experimental band maxima of the $v(\mathrm{Rh} \rightarrow \mathrm{Mo})$ transitions for the complexes with $\pi$-acid ligands (2-8) were observed at higher energies, as compared with the maxima of the complexes with $\sigma$-only electron donor ligands (9-11).

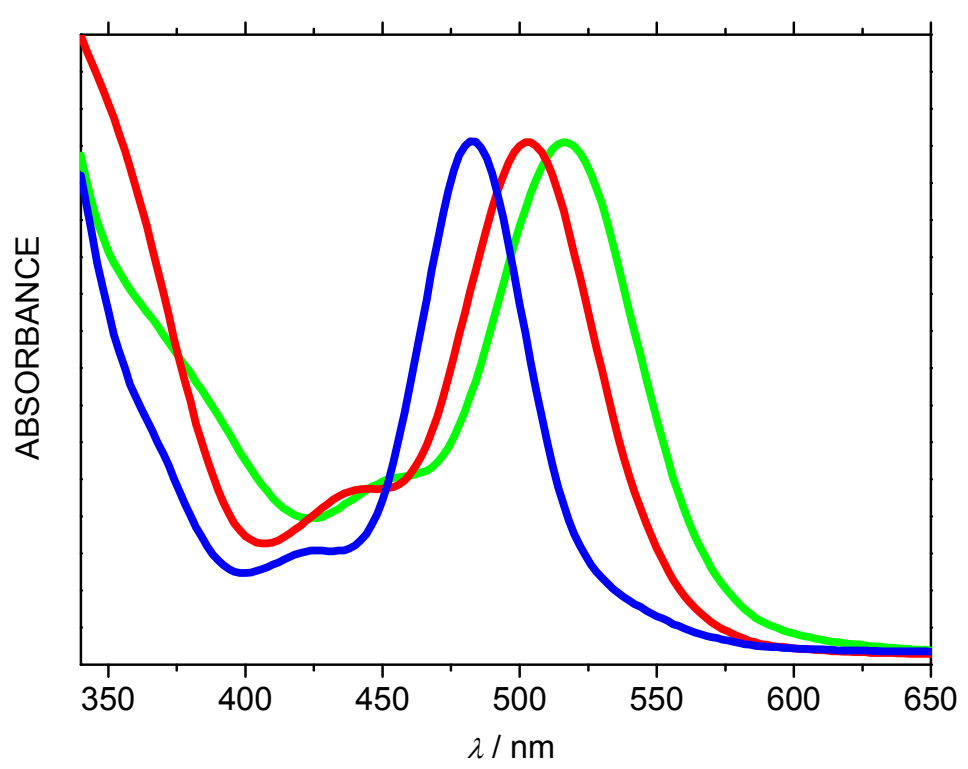

Figure 3. Electronic absorption spectra of complexes 2 (COD, red), $3(\mathrm{CO}$, blue $)$ and $\mathbf{4}\left(\mathrm{P}(\mathrm{OPh})_{3}\right.$, green). (Arbitary absorbance scale). 
Table 3. UV-Vis and ${ }^{31} \mathrm{P}$ NMR spectroscopic data of tetrathiomolybdatorhodium complexes

\begin{tabular}{|c|c|c|c|c|}
\hline \multirow{2}{*}{ Complex } & \multirow{2}{*}{$\frac{\mathrm{UV}-\mathrm{Vis}^{a}}{\mathrm{r}(\mathrm{Rh} \rightarrow \mathrm{Mo}) / \mathrm{nm}}$} & \multicolumn{3}{|c|}{${ }^{31} \mathrm{P} \mathrm{NMR}^{b}$} \\
\hline & & $\delta(\mathrm{P}) / p p m$ & $\Delta \delta(\mathrm{P}) / \mathrm{ppm}$ & ${ }^{1} J(\mathrm{Rh}-\mathrm{P}) / H z$ \\
\hline 2 & 508 & & & \\
\hline 3 & 483 & & & \\
\hline 4 & 524 & 127.67 & -2.84 & 281.9 \\
\hline 5 & 527 & 126.23 & -6.83 & 283.2 \\
\hline 6 & 542 & 150.46 & 8.65 & 258.0 \\
\hline 7 & 551 & 144.98 & 5.18 & 256.1 \\
\hline 8 & 557 & 142.47 & 2.04 & 256.6 \\
\hline 9 & 563 & 80.50 & 82.89 & 165.9 \\
\hline 10 & 576 & 70.48 & 102.85 & 163.0 \\
\hline 11 & 571 & 36.33 & 52.04 & 164.3 \\
\hline
\end{tabular}

The electronic spectra were studied by time-dependent DFT (TDDFT) calculations. Table 4 gives the major predicted transitions with the excitation energy $(E)$, oscillator strength (f), dominant configuration contribution, and assignment. According to the TDDFT predictions the main band in the $\mathrm{Vis}$ is assigned to the spin allowed (HOMO $)^{2} \rightarrow(\mathrm{HOMO})^{1}(\mathrm{LUMO})^{1}$ transition, which is actually a $v(\mathrm{Rh} \rightarrow \mathrm{Mo})$ electron transfer transition with minor $\mathrm{S}_{\mathrm{br}} \rightarrow$ Mo (br: bridging) contribution. For complex 3 the $v(\mathrm{Rh} \rightarrow \mathrm{Mo})$ transition is assigned to the $(\mathrm{HOMO})^{2} \rightarrow(\mathrm{HOMO})^{1}(\mathrm{LUMO}+1)^{1}$ transition. The lower energy shoulder in the experimental spectra could be assigned to $\mathrm{S}_{\text {term }} \rightarrow$ Mo (term: terminal) transition and the higher energy shoulder mainly to other $\mathrm{Rh} \rightarrow \mathrm{Mo}$ transition(s). The results of the calculations confirm the trend of the variation of the experimental $v(\mathrm{Rh} \rightarrow \mathrm{Mo})$ data. 
Furthermore, the regression analysis of the experimental $v(\mathrm{Rh} \rightarrow \mathrm{Mo})$ values to the computed ground state configuration HOMO-LUMO energy gap for complexes $\mathbf{2 , 3}, \mathbf{4}, \mathbf{6}, \mathbf{7}$, and $\mathbf{8}$, shows a linear correlation, equation 1 (Figure 4 shows the resulting linear fit):

$$
v_{\exp }(\mathrm{Rh} \rightarrow \mathrm{Mo}) / 10^{3} \cdot \mathrm{cm}^{-1}=-19.50293+1.39457 \cdot \Delta E(\mathrm{HOMO}-\mathrm{LUMO}) / 10^{3} \cdot \mathrm{cm}^{-1} \quad\left(\mathrm{R}^{2}=0.901\right)
$$

It is thus obvious that by tuning the donor-acceptor properties of the auxiliary ligands of the rhodium atom, a predictable fine-tune of the electronic properties of the corresponding TTMR complexes seems to take place.

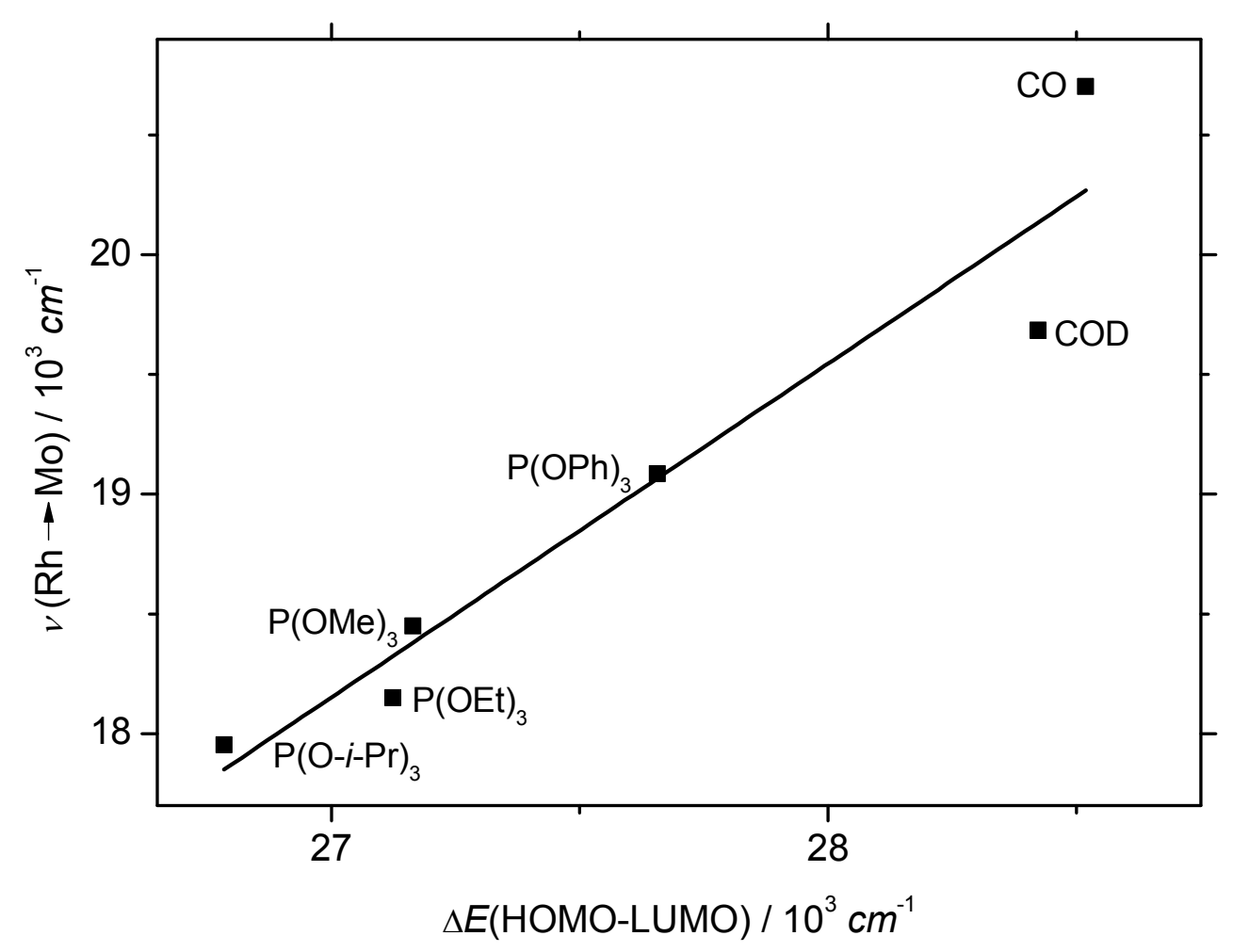

Figure 4. Correlation between experimental $v(\mathrm{Rh} \rightarrow \mathrm{Mo})$ and computed ground state $\Delta E($ HOMO-LUMO). 
Table 4. Excitation Energy (E), Oscillator Strength (f), Dominant Contributing Transitions and Associated Percent Contribution, and Assignment of Complexes 3, 6, 7 and $\mathbf{8}^{a}$

\begin{tabular}{|c|c|c|c|c|c|}
\hline$S_{n}$ & $E / \mathrm{eV}$ & $E / \mathrm{nm}$ & $\mathrm{f}$ & dominant transitions (contribution $\%)^{b}$ & assignment $^{c}$ \\
\hline \multicolumn{6}{|c|}{ Complex 3} \\
\hline 3 & 2.65 & 469 & 0.0078 & HOMO-1 $\rightarrow$ LUMO (88\%) & $\mathrm{S}_{\mathrm{t}} \rightarrow \mathrm{Mo}$ \\
\hline 4 & 2.86 & 434 & 0.0355 & HOMO $\rightarrow$ LUMO+1 (92\%) & $\mathrm{Rh}, \mathrm{S}_{\mathrm{br}} \rightarrow \mathrm{Mo}$ \\
\hline 9 & 3.43 & 361 & 0.0237 & HOMO-1 $\rightarrow$ LUMO+2 (98\%) & $\mathrm{S}_{\mathrm{t}} \rightarrow \mathrm{Mo}, \mathrm{C}(\mathrm{CO})$ \\
\hline 12 & 3.60 & 344 & 0.0188 & HOMO-2 $\rightarrow$ LUMO+2 (72\%) & $\mathrm{Rh} \rightarrow \mathrm{C}(\mathrm{CO})$ \\
\hline 20 & 3.94 & 315 & 0.0125 & $\mathrm{HOMO} \rightarrow \mathrm{LUMO}+6(75 \%)$ & $\mathrm{Rh}, \mathrm{S}_{\mathrm{br}} \rightarrow \mathrm{Mo}$ \\
\hline \multicolumn{6}{|c|}{ Complex 6} \\
\hline 4 & 2.64 & 469 & 0.0398 & HOMO $\rightarrow$ LUMO (84\%) & $\mathrm{Rh}, \mathrm{S}_{\mathrm{br}} \rightarrow \mathrm{Mo}$ \\
\hline 5 & 2.78 & 445 & 0.0118 & HOMO-1 $\rightarrow$ LUMO+1 (76\%) & $\mathrm{S}_{\mathrm{t}} \rightarrow \mathrm{Mo}$ \\
\hline 7 & 3.21 & 386 & 0.0091 & HOMO-3 $\rightarrow$ LUMO+2 (64\%) & $\mathrm{Rh} \rightarrow \mathrm{Mo}, \mathrm{P}$ \\
\hline 10 & 3.33 & 373 & 0.0053 & HOMO-2 $\rightarrow$ LUMO (79\%) & $\mathrm{Rh}, \mathrm{P} \rightarrow \mathrm{Mo}$ \\
\hline 19 & 3.76 & 330 & 0.0039 & HOMO-5 $\rightarrow$ LUMO+1 (65\%) & $\mathrm{Rh}, \mathrm{P} \rightarrow \mathrm{Mo}$ \\
\hline \multicolumn{6}{|c|}{ Complex 7} \\
\hline 2 & 2.45 & 506 & 0.0536 & HOMO $\rightarrow$ LUMO (85\%) & $\mathrm{Rh}, \mathrm{S}_{\mathrm{br}} \rightarrow \mathrm{Mo}$ \\
\hline 5 & 2.74 & 452 & 0.0142 & HOMO-1 $\rightarrow$ LUMO+1 (74\%) & $\mathrm{S}_{\mathrm{t}} \rightarrow \mathrm{Mo}$ \\
\hline 7 & 2.95 & 420 & 0.0103 & HOMO-2 $\rightarrow$ LUMO (79\%) & $\mathrm{Rh} \rightarrow \mathrm{Mo}, \mathrm{S}_{\mathrm{t}}$ \\
\hline 9 & 3.08 & 403 & 0.0079 & HOMO-2 $\rightarrow$ LUMO+2 (63\%) & $\mathrm{Rh} \rightarrow \mathrm{Mo}, \mathrm{P}$ \\
\hline \multirow[t]{2}{*}{11} & 3.17 & 391 & 0.0076 & HOMO-3 $\rightarrow$ LUMO (29\%) & $\mathrm{Rh} \rightarrow \mathrm{Mo}, \mathrm{P}$ \\
\hline & & & & HOMO-3 $\rightarrow$ LUMO+1 (47\%) & $\mathrm{Rh} \rightarrow \mathrm{Mo}$ \\
\hline 14 & 3.48 & 357 & 0.0076 & $\mathrm{HOMO} \rightarrow \mathrm{LUMO}+3(63 \%)$ & $\mathrm{Rh}, \mathrm{S}_{\mathrm{br}}, \mathrm{S}_{\mathrm{t}} \rightarrow \mathrm{Mo}, \mathrm{P}$ \\
\hline 18 & 3.61 & 343 & 0.0274 & HOMO-4 $\rightarrow$ LUMO+1 (88\%) & $\mathrm{S}_{\mathrm{t}} \rightarrow \mathrm{Mo}$ \\
\hline \multicolumn{6}{|c|}{ Complex 8} \\
\hline \multirow[t]{2}{*}{2} & 2.37 & 523 & 0.0520 & HOMO $\rightarrow$ LUMO (54\%) & $\mathrm{Rh}, \mathrm{S}_{\mathrm{br}} \rightarrow \mathrm{Mo}$ \\
\hline & & & & HOMO $\rightarrow$ LUMO+1 26(\%) & $\mathrm{Rh}, \mathrm{S}_{\mathrm{br}} \rightarrow \mathrm{Mo}$ \\
\hline 3 & 2.42 & 512 & 0.0070 & $\mathrm{HOMO} \rightarrow \mathrm{LUMO}+2(83 \%)$ & $\mathrm{Rh}, \mathrm{S}_{\mathrm{t}} \rightarrow \mathrm{Mo}, \mathrm{P}$ \\
\hline 5 & 2.71 & 458 & 0.0100 & HOMO-1 $\rightarrow$ LUMO (76\%) & $\mathrm{S}_{\mathrm{t}} \rightarrow \mathrm{Mo}$ \\
\hline \multirow[t]{2}{*}{9} & 3.05 & 406 & 0.0075 & HOMO-2 $\rightarrow$ LUMO (65\%) & $\mathrm{Rh}, \mathrm{P} \rightarrow \mathrm{Mo}$ \\
\hline & & & & HOMO-2 $\rightarrow$ LUMO+1 (26\%) & $\mathrm{Rh}, \mathrm{P} \rightarrow \mathrm{Mo}$ \\
\hline \multirow[t]{2}{*}{10} & 3.10 & 400 & 0.0229 & HOMO-3 $\rightarrow$ LUMO+1 (42\%) & $\mathrm{Rh} \rightarrow \mathrm{Mo}, \mathrm{S}_{\mathrm{t}}$ \\
\hline & & & & HOMO-2 $\rightarrow$ LUMO+2 (30\%) & $\mathrm{Rh} \rightarrow \mathrm{Mo}$ \\
\hline 14 & 3.37 & 367 & 0.0119 & HOMO-4 $\rightarrow$ LUMO (78\%) & $\mathrm{Rh} \rightarrow \mathrm{Mo}$ \\
\hline 17 & 3.50 & 355 & 0.0342 & HOMO-4 $\rightarrow$ LUMO+1 (70\%) & $\mathrm{Rh} \rightarrow \mathrm{Mo}$ \\
\hline
\end{tabular}




\begin{abstract}
${ }^{31}$ P NMR Spectroscopy. The ${ }^{31} \mathrm{P}$ NMR spectra of the complexes 4-11 consist of a doublet, indicative of the equivalence of the phosphorus nuclei in solution (Table 3). The coordination chemical shift, $\Delta \delta\left({ }^{31} \mathrm{P}\right)$, equal to the difference of the chemical shift upon coordination, $\delta\left({ }^{31} \mathrm{P}\right)_{\mathrm{c}}$, and the chemical shift of the free phosphorus ligand, $\delta\left({ }^{31} \mathrm{P}\right)_{\mathrm{f}}$, of the phosphite-complexes in comparison with the diphosphine-complexes were found to depend on a distinct manner on the nature of the ligands, the former having small positive or negative values and the latter large positive values. This is in accordance with the well known tendency that the ${ }^{31} \mathrm{P}$ chemical shift for $\sigma$-donor phosphines moves by a large amount toward high frequency upon coordination, while for $\pi$-acceptor (also weak $\sigma$-donors) phosphites the chemical shift moves by a small amount toward high or low frequency upon coordination. ${ }^{22}$ As far as the spin-spin coupling constants, ${ }^{1} J(\mathrm{Rh}-\mathrm{P})$, are concerned, they were found to be significantly larger for the phosphitecomplexes in comparison to those of the diphosphine complexes, in agreement with the experimental observation according which phosphite ligands cause in general $50-100 \%$ larger ${ }^{1} J(\mathrm{M}-\mathrm{P})$ coupling constant compared to analogous phosphine ligands. ${ }^{23}$
\end{abstract}

$v(\mathbf{R h} \rightarrow \mathrm{Mo})$ as Ligand Electronic Parameter. Since the $v(\mathrm{Rh} \rightarrow \mathrm{Mo})$ transition of the TTMR complexes respond sensitively to phosphite alterations (Table 3), we proceeded to the study of this electronic transition as candidate parameter for the quantification of the electron donoracceptor properties of the ligands in question. It should be mentioned that the transition metal complexes and organometallic compounds of $\mathrm{Rh}(\mathrm{I})$ with phosphorus ligands only occasionally were of interest from the point of view of electronic spectroscopy, since they usually absorb in the UV and the spectral region available for the measurement of the spectra is limited by the cutoff limit of the solvent used. 
The best known spectroscopic description of the electronic effects of trivalent phosphorus ligands is Tolman's electronic parameter (TEP). ${ }^{20,24}$ Tolman have shown that the band maximum of the $A_{1} v(C O)$ vibration of $\left[N i(C O)_{3} L\right]\left(L=P R^{l} R^{2} R^{3}\right)$ in the IR, can be expressed in terms of empirical parameters, which describe the effects of phosphorus substituents, according to equation 2:

$$
v \mathrm{CO}_{\mathrm{Ni}}=2056.1+\sum \chi_{j}
$$

where $v \mathrm{CO}_{\mathrm{Ni}}$ refers to the $\mathrm{A}_{1} v(\mathrm{CO})$ band, $2056.1 \mathrm{~cm}^{-1}$ is the $\mathrm{A}_{1}$ band of $\left[\left[\mathrm{Ni}(\mathrm{CO})_{3}\left(\mathrm{PBu}_{3}^{t}\right)\right]\right.$ and $\chi_{j}$ is a parameter which describes the contribution of the $\mathrm{R}^{j}$ substituent of the phosphorus ligand on the $\mathrm{CO}$ stretching frequency of $\left[\mathrm{Ni}(\mathrm{CO})_{3} \mathrm{~L}\right] .{ }^{20 \mathrm{a}}$ The term TEP is used to describe either $\sum \chi_{j}$ $($ symb. $X)$ or $v \mathrm{CO}_{\mathrm{Ni}}$. Bartik et al. re-evaluated and extended Tolman's $v \mathrm{CO}_{\mathrm{Ni}}$ data bank by using FT-IR measurements and derived a new set of more accurate TEP values, ${ }^{\mathrm{FT}} X{ }^{25}$ Although the differences between the two sets of $v \mathrm{CO}_{\mathrm{Ni}}$ values for the phosphites studied in the present work are less than $1.4 \mathrm{~cm}^{-1}$, we have used Bartik's data for the sake of accuracy.

It is generally accepted that the variation of the $\mathrm{A}_{1} v \mathrm{CO}_{\mathrm{Ni}}$ can be attributed to the variation of the electron donor-acceptor properties of the phosphorus ligands; the stronger donor phosphorus ligands increase the electron density on $\mathrm{Ni}$, which passes some of this increase along to the COs by back donation. This, in turn, lowers $v(\mathrm{CO})_{\mathrm{Ni}}$. Thus, TEP describes the net donating ability of the phosphorus ligands satisfactorily. ${ }^{26}$ Since many important ligands do not give the required stable $\left[\mathrm{Ni}(\mathrm{CO})_{3} \mathrm{~L}\right]$ complex, there have been efforts to overcome this obstacle by means of the "computational way". ${ }^{26 a}$ More detailed theoretical studies of the nature of the variation of $v(\mathrm{CO})_{\mathrm{Ni}}$ have been reported recently. ${ }^{26 \mathrm{~b}}$ The TEP concept has been also proposed as an alternative and effective way of determining the electronic communication between metals in bimetallic organometallic compounds. ${ }^{27}$ 
With the introduction of bidentate chelating phosphorus ligands the $\left[\mathrm{Ni}(\mathrm{CO})_{3} \mathrm{~L}\right]$ based scale of Tolman was no longer applicable. In 1983 Crabtree et al. have shown that the highest $v(\mathrm{CO})$ band of the IR spectrum of the $c i s-\left[\mathrm{Mo}(\mathrm{CO})_{4} \mathrm{~L}_{2}\right]$ (L: monodentate phosphorus ligand) complexes correlate linearly with the $v \mathrm{CO}_{\mathrm{Ni}}$ values,

$$
v \mathrm{CO}_{\mathrm{Ni}}=v \mathrm{CO}_{\mathrm{Mo}}+871
$$

Thus, a new scale was introduced, based on cis- $\left[\mathrm{Mo}(\mathrm{CO})_{4} \mathrm{~L}-\mathrm{L}\right]$ (L-L: bidentate ligand or two monodentate ligands) complexes, which could be used not only for monodentate and bidentate phosphorus ligands but also for olefinic and diolefinic ligands provided that the respective complexes could be prepared. ${ }^{28}$

Apart from the IR methods based on the $v \mathrm{CO}$ stretching frequency, ${ }^{24 \mathrm{~b}}$ Cotton, Turner et al. have examined the predictive power of $\mathrm{UV}-\mathrm{V}$ is spectral data of $\left[\mathrm{Cr}(\mathrm{CO})_{5} \mathrm{~L}\right](\mathrm{L}$ : phosphorus and nitrogen ligands) complexes for the direct evaluation of the $\pi$-bonding in metal carbonyls, for which they have concluded to have only qualitative ability. ${ }^{29}$

The energies of the $v(\mathrm{Rh} \rightarrow \mathrm{Mo})$ transitions of complexes 4-8 were found to correlate linearly with Tolman's electronic parameter (Table 5) according to equation 4 (Figure 5 shows the resulting linear fit):

$$
\begin{aligned}
& v(\mathrm{Rh} \rightarrow \mathrm{Mo}) / \mathrm{cm}^{-1}=15940.4+104.111 \cdot{ }^{\mathrm{FT}} X\left(\mathrm{R}^{2}=0.996\right) \\
& \left(\mid \lambda_{\max }(\exp )-\lambda_{\max }(\text { calc }) \mid \leq 1 \mathrm{~nm}\right)
\end{aligned}
$$

This linear correlation shows that the two parameters, $v(\mathrm{Rh} \rightarrow \mathrm{Mo})$ and ${ }^{\mathrm{FT}} X$, are in very close agreement, so that it can be argued that they describe the same property of the ligands, namely the net donating ability. The observed transferability between $v(\mathrm{Rh} \rightarrow \mathrm{Mo})$ and ${ }^{\mathrm{FT}} X$, suggests that $\pi$ effects are comparable in importance in the respective systems, $\left[\mathrm{L}_{2} \mathrm{RhS}_{2} \mathrm{MoS}_{2}\right]^{-}$and $\left[\mathrm{Ni}(\mathrm{CO})_{3} \mathrm{~L}\right]$ 


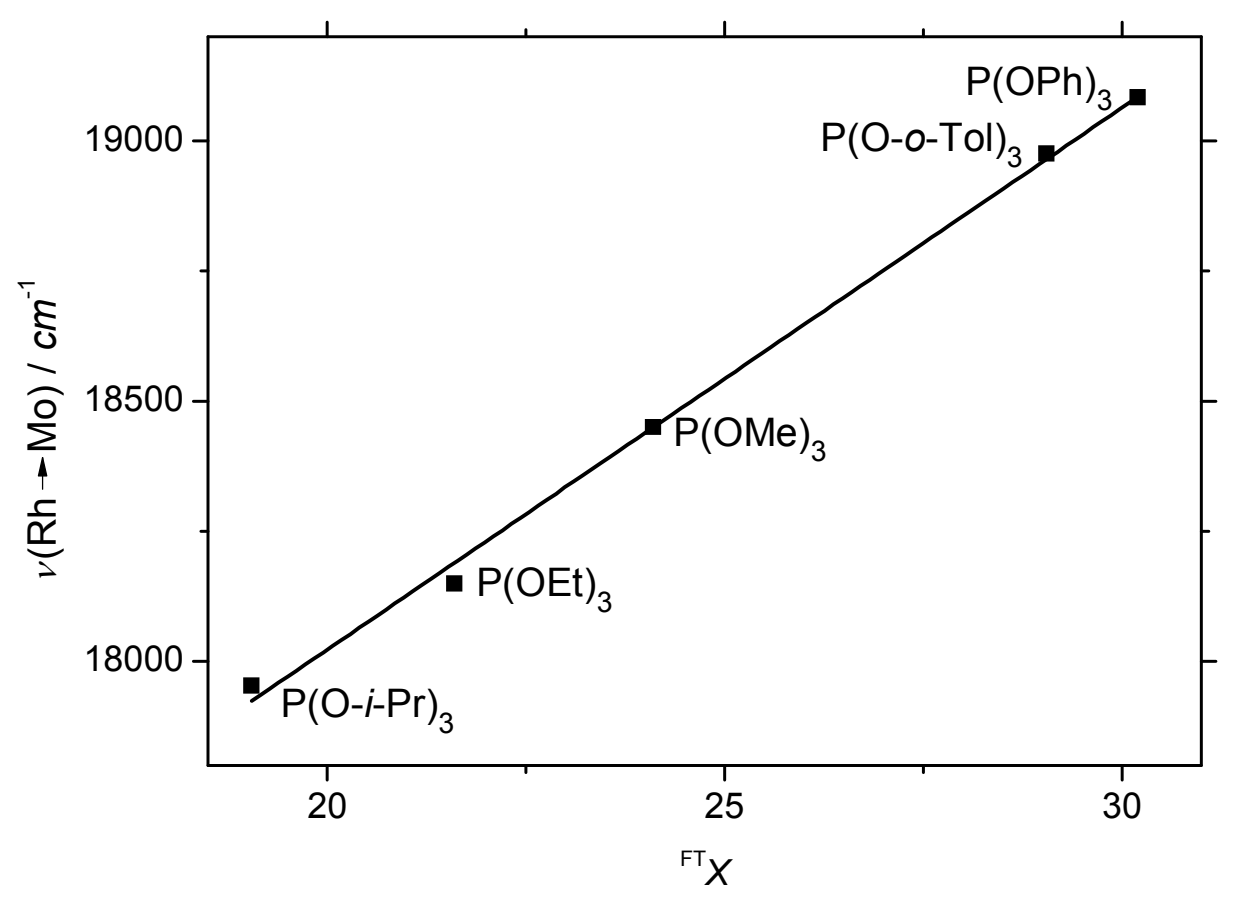

Figure 5. Correlation between $v(\mathrm{Rh} \rightarrow \mathrm{Mo})$ and ${ }^{\mathrm{FT}} X$.

As shown above, the variation of $v(\mathrm{Rh} \rightarrow \mathrm{Mo})$ is attributed to the tuning of the HOMO-LUMO gap, as a result of the variation of the donor-acceptor properties of the phosphorus ligands. It can thus be argued that $v(\mathrm{Rh} \rightarrow \mathrm{Mo})$ is a well defined electronic parameter for monodentate and bidentate ligands, provided that they give the required complexes. For the ligands studied in this work the variation of the net donating ability according to $v(\mathrm{Rh} \rightarrow \mathrm{Mo})$ has as follows: $\mathrm{CO}<\mathrm{COD}<\mathrm{P}(\mathrm{OPh})_{3}<\mathrm{P}(\mathrm{O}-o-\mathrm{Tol})_{3}<\mathrm{P}(\mathrm{OMe})_{3}<\mathrm{P}(\mathrm{OEt})_{3}<\mathrm{P}(\mathrm{O}-i-\mathrm{Pr})_{3}<c i s$-dppen $<$ dppb $<$ dppe 
Quantitative Analysis of Ligand Effects of the ${ }^{31} \mathbf{P}$ NMR Parameters. In addition to $v(\mathrm{Rh} \rightarrow \mathrm{Mo})$, the ${ }^{31} \mathrm{P}$ NMR spectral parameters $\left(\delta\left({ }^{31} \mathrm{P}\right), \Delta \delta\left({ }^{31} \mathrm{P}\right)\right.$ and $\left.{ }^{1} J(\mathrm{Rh}-\mathrm{P})\right)$, of the complexes also respond sensitively to alterations of the phosphite ligands (Table 3). In particular, it appears that although ${ }^{1} J(\mathrm{Rh}-\mathrm{P})$ vary roughly parallel to the $\pi$-acidity of the phosphites, the variation of $\delta\left({ }^{31} \mathrm{P}\right)$ and $\Delta \delta\left({ }^{31} \mathrm{P}\right)$ seems to be more complicated.

The ${ }^{31} \mathrm{P}$ NMR spectral parameters have been widely employed for the interpretation of metalphosphorus bonds of transition metal complexes and organometallic compounds in terms of $\sigma$ and $\pi$-bonding interactions. ${ }^{20 \mathrm{~b}, 22,23,24 a, 33}$

The ${ }^{31} \mathrm{P}$ NMR chemical shifts of free and of coordinated phosphorus(III) ligands are thought to arise primarily from variations in the paramagnetic contribution from electrons in valence orbitals. ${ }^{30}$ This was supported by the elaborate theoretical study of $\Delta \delta\left({ }^{31} \mathrm{P}\right)$ for the phosphinesubstituted metal carbonyl complexes of the type $\left[\mathrm{M}(\mathrm{CO})_{5} \mathrm{PR}_{3}\right](\mathrm{M}=\mathrm{Cr}, \mathrm{Mo} ; \mathrm{R}=\mathrm{H}, \mathrm{Me}, \mathrm{Ph}, \mathrm{F}, \mathrm{Cl})$ by Morales and Ziegler. ${ }^{31}$ The interpretation of the results of these theoretical calculations has revealed that: (i) for complexes with $\sigma$ donors (alkyl or phenyl phosphine) $\Delta \delta$ is positive (with the poorest donors affording the largest values for $\Delta \delta$ ), while the result of back-donation (as in $\mathrm{PCl}_{3}$ ) is negative contributions to $\Delta \delta$, and (ii) $\Delta \delta$ should be to a first approximation inversely proportional to the HOMO-LUMO energy gap.

The magnitude of the ${ }^{1} J(\mathrm{M}-\mathrm{P})$ has been attributed to the $s$ character of the M-P bond. ${ }^{22,23,33}$ It has been reported that the complexes with isosteric phosphines $\left[\mathrm{RhCl}\left(\eta^{4}-\mathrm{COD}\right)\left(\mathrm{P}\left(4-\mathrm{XC}_{6} \mathrm{H}_{4}\right)_{3}\right)\right]$ $\left(\mathrm{X}=\mathrm{OCH}_{3}, \mathrm{CH}_{3}, \mathrm{H}, \mathrm{F}, \mathrm{Cl}\right.$, and $\left.\mathrm{CF}_{3}\right)$, show a linear relation between ${ }^{1} J(\mathrm{Rh}-\mathrm{P})$ and the $\sigma$-electron donicity of the ligands, as described by the QALE parameter $\chi_{\mathrm{d}}$, vide infra. ${ }^{34}$ This is in accordance with the dominant role of the $s$ character, since strong $\sigma$-donation is usually associated with high ratio of $p / s$ character in the lone pair. ${ }^{22,35}$ 
According to the above discussion, the variation of the ${ }^{31} \mathrm{P}$ NMR spectral parameters should be examined in light of suitable parameters related to the $\sigma$ - and $\pi$-bonding capacity of the phosphite ligands. Such parameters are provided by the QALE model, which was invented and developed by Giering et al. $^{36}$ The QALE model has succeeded in the resolution of the net donating ability of a ligand in terms of the stereoelectronic parameters $\chi_{\mathrm{d}}, \pi_{\mathrm{p}}, E_{\mathrm{ar}}$ and $\theta$, which are defined as follows:

$\chi_{\mathrm{d}}$ - describes the $\sigma$ electron donor capacity (a small $\chi_{\mathrm{d}}$ value means a good $\sigma$ electron donor $)^{35 \mathrm{~d}}$

$\pi_{\mathrm{p}}$ - describes the $\pi$ electron acceptor capacity (a large value indicates a strong $\pi$ acid); ${ }^{36 \mathrm{k}}$

$E_{\text {ar }}$ - secondary electronic effect (origin unknown); ${ }^{36 e}$

$\theta$ - Tolman's cone angle (a large value of $\theta$ is associated with a large ligand). ${ }^{20 \mathrm{~b}, 37}$

A fundamental tenet of QALE is that a physicochemical property of a complex can be expressed as a linear relationship in terms of the stereoelectronic parameters of the ligands according to an equation of the form:

$$
\text { property }=\mathrm{a} \cdot \chi_{\mathrm{d}}+\mathrm{b} \cdot \pi_{\mathrm{p}}+\mathrm{c} \cdot E_{\mathrm{ar}}+\mathrm{d} \cdot\left(\theta-\theta_{\mathrm{st}}\right)+\mathrm{e}
$$

where $\theta_{\mathrm{st}}$ is the steric threshold.

In the absence of a steric threshold equation 5 reduces to equation 6 :

$$
\text { property }=\mathrm{a} \cdot \chi_{\mathrm{d}}+\mathrm{b} \cdot \pi_{\mathrm{p}}+\mathrm{c} \cdot E_{\mathrm{ar}}+\mathrm{d}
$$

The acceptability of a multiparametric regression equation of the above form relies on statistical criteria.

Although it has been stressed for some time that "regarding the ${ }^{31} \mathrm{P}$ chemical shifts it stands to reason that the QALE parameters exert a similar influence to the chemical shift in the NMR spectrum as they do to the $v(\mathrm{CO})$ vibrations in the IR spectrum", ${ }^{23}$ the successful 
parameterization of the ${ }^{31} \mathrm{P}$ NMR chemical shifts (or of the coordination chemical shifts) of coordinated phosphorus ligands in terms of the QALE parameters has never, to our knowledge, been reported to date. In our opinion, one of the reasons about this lies in the choice of the spectral parameter under examination. Thus, before proceeding to the study of the QALE correlation of the chemical shifts, we should question on the suitability of $\delta(\mathrm{P})$ and/or $\Delta \delta(\mathrm{P})$ for such a task. ${ }^{23,31}$

The chemical shift of a nucleus ( $\left.\delta_{\text {sample }}\right)$ is measured relative to an arbitrary (and convenient) reference and can be written with sufficient accuracy as

$$
\delta_{\text {sample }}=\sigma_{\text {reference }}-\sigma_{\text {sample }}
$$

where $\sigma$ is the shielding constant. Thus, the measured value of $\delta_{\text {sample }}$ is an arbitrary number, since it depends on the reference used.

The coordination of a ligand is accompanied by changes in the chemical shifts of the ligand nuclei and these effects can be analyzed in terms of the coordination chemical shift, $\Delta \delta$, which is independent of the reference used, since

$$
\Delta \delta=\sigma_{\text {free ligand }}-\sigma_{\text {coordinated ligand }}
$$

According to the above, since a QALE correlation provides the quantification of the individual effects induced as a result of the coordination of the ligand under consideration, the suitable parameter should be $\Delta \delta(\mathrm{P})$, because it describes the difference in the shielding of the free ligand and the ligand in the complex.

Since the phosphites we are dealing with are sterically unhindered $\left(107^{\circ}<\theta<141^{\circ}\right)$ and given the electronic nature of the properties under consideration, the dependence of the ${ }^{31} \mathrm{P} N M R$ parameters on steric effects could be precluded to a first approximation. 
Table 5. Stereoelectronic parameters of phosphite ligands

$\begin{array}{llllll}\text { Phosphite } & { }^{\mathrm{FT}} X^{a} & \chi_{\mathrm{d}}^{b} & E_{\mathrm{ar}}{ }^{b} & \pi_{\mathrm{p}}^{b} & \begin{array}{l}\theta^{c} \\ \mathrm{deg}\end{array} \\ \mathrm{P}(\mathrm{OPh})_{3} & 30.20 & 23.6 & 1.3 & 4.1 & 128 \\ \mathrm{P}(\mathrm{O}-o-\mathrm{Tol})_{3} & 29.05 & 23.2^{d} & 1.4^{d} & 4.3^{d} & 141^{e} \\ \mathrm{P}(\mathrm{OMe})_{3} & 24.10 & 17.9 & 1.0 & 2.8 & 107 \\ \mathrm{P}(\mathrm{OEt})_{3} & 21.60 & 15.8 & 1.1 & 2.9 & 109 \\ \mathrm{P}(\mathrm{O}-i-\mathrm{Pr})_{3} & 19.05 & 13.4 & 1.3 & 2.9 & 130\end{array}$

${ }^{a}$ Ref. $25 ;{ }^{b}$ Ref. $36 \mathrm{k} ;{ }^{c}$ Ref. $20 \mathrm{~b} ;{ }^{d}$ This work (SI.7 in Supporting Information); ${ }^{e}$ Ref. 38

The examination of the correlations of $\Delta \delta(\mathrm{P})$ and ${ }^{1} J(\mathrm{Rh}-\mathrm{P})$ for complexes $4-8$ with respect to the QALE model parameters (Table 5), resulted in the following statistically significant correlations, (Statistical Analysis of the QALE Multiple Regressions is given in SI.7 in Supporting Information):

$$
\begin{aligned}
& \Delta \delta(\mathrm{P}) / p p m=28.1382+1.18668 \cdot \chi_{\mathrm{d}}-14.4659 \cdot \pi_{\mathrm{p}}\left(\mathrm{R}^{2}=0.998\right) \\
& (\mid \Delta \delta(\mathrm{P})(\mathrm{exp})-\Delta \delta(\mathrm{P})(\text { calc }) \mid \leq 0.32 \mathrm{ppm}) \\
& \Delta \delta(\mathrm{P}) / p p m \cdot \Delta E / 10^{-4} \cdot \mathrm{cm}^{-1}=52.2651+2.21402 \cdot \chi_{\mathrm{d}}-26.9752 \cdot \pi_{\mathrm{p}}\left(\mathrm{R}^{2}=0.998\right) \\
& (\Delta E \text { is the band maximum of } v(\mathrm{Rh} \rightarrow \mathrm{Mo})) \\
& { }^{1} J(\mathrm{Rh}-\mathrm{P}) / H z=183.05+2.44616 \cdot \chi_{\mathrm{d}}+31.288 \cdot E_{\mathrm{ar}}\left(\mathrm{R}^{2}=1.000\right) \\
& \left(\mid{ }^{1} J(\mathrm{Rh}-\mathrm{P})(\exp )-{ }^{1} J(\mathrm{Rh}-\mathrm{P})(\text { calc }) \mid \leq 0.4 \mathrm{~Hz}\right)
\end{aligned}
$$


Our analysis for $\Delta \delta(\mathrm{P})$ would indicate that:

1. Both the $\sigma$ electron donor capacity $\left(\chi_{\mathrm{d}}\right)$ and the $\pi$ electron acceptor capacity $\left(\pi_{\mathrm{p}}\right)$ of the phosphites seem to be equally important in determining the sign and the magnitude of the coordination chemical shift, $\Delta \delta(\mathrm{P})$, implying a dependence of the form:

$$
\Delta \delta(\mathrm{P})=\text { constant }+\Delta \delta^{\sigma}(\mathrm{P})+\Delta \delta^{\pi}(\mathrm{P})
$$

since $\Delta E$ exhibit minor change.

2. As shown in Table 6 , the result of the $\sigma$ bonding interaction $(\mathrm{P} \rightarrow \mathrm{Rh})$ is the shift of $\delta(\mathrm{P})$ towards higher frequencies $\left(\Delta \delta^{\sigma}(\mathrm{P})>0\right)$ while that of the $\pi$ bonding interaction $(\mathrm{P} \leftarrow \mathrm{Rh})$ is the shift of $\delta(\mathrm{P})$ towards lower frequencies $\left(\Delta \delta^{\pi}(\mathrm{P})<0\right)$.

3. Both $\Delta \delta^{\sigma}(\mathrm{P})$ and $\Delta \delta^{\pi}(\mathrm{P})$ vary antiparallel to the $\sigma$ donicity and the $\pi$ acidity of the phosphite, respectively, i.e. the poorest donors afford the largest (positive) values of $\Delta \delta^{\sigma}(\mathrm{P})$ while the strongest acceptors afford smallest (negative) values of $\Delta \delta^{\pi}(\mathrm{P})$, as depicted in Scheme 4.

4. The coordination chemical shifts for the sterically unhindered phosphites under consideration seem to be independent of the steric parameter $\theta$.

These results are in excellent agreement with the results of the theoretical calculations mentioned above. ${ }^{31}$ 
Table 6. Calculated contributions to the $\Delta \delta(\mathrm{P})$ and ${ }^{1} J(\mathrm{Rh}-\mathrm{P})$ values according to the QALE correlations.

\begin{tabular}{lllll} 
Complex & $\Delta \delta^{\sigma}(\mathrm{P})^{a}$ & $\Delta \delta^{\pi}(\mathrm{P})^{b}$ & ${ }^{1} J^{\sigma}(\mathrm{Rh}-\mathrm{P})^{c}$ & ${ }^{1} J^{\mathrm{ar}}(\mathrm{Rh}-\mathrm{P})^{d}$ \\
$\mathbf{4}$ & 28.01 & -59.31 & 57.7 & 40.7 \\
$\mathbf{5}$ & 27.53 & -62.20 & 56.8 & 43.8 \\
$\mathbf{6}$ & 21.24 & -40.50 & 43.8 & 31.3 \\
7 & 18.75 & -41.95 & 38.6 & 34.4 \\
$\mathbf{8}$ & 15.90 & -41.95 & 32.8 & 40.7 \\
& & & & \\
${ }^{a} \Delta \delta^{\sigma}(\mathrm{P})=1.18668 \cdot \chi_{\mathrm{d}} ;{ }^{b} \Delta \delta^{\pi}(\mathrm{P})=-14.4659 \cdot \pi_{\mathrm{p}} ;{ }^{c}{ }^{1} J^{\sigma}(\mathrm{Rh}-\mathrm{P})=2.44616 \cdot \chi_{\mathrm{d}} ;{ }^{d}{ }^{1} J^{\mathrm{ar}}(\mathrm{Rh}-\mathrm{P})=31.288 \cdot E_{\mathrm{ar}}$ \\
\hline
\end{tabular}

Scheme 4. Variation of $\Delta \delta(\mathrm{P})$ with $\sigma$-donor and $\pi$-acceptor capacities of phosphite ligands.

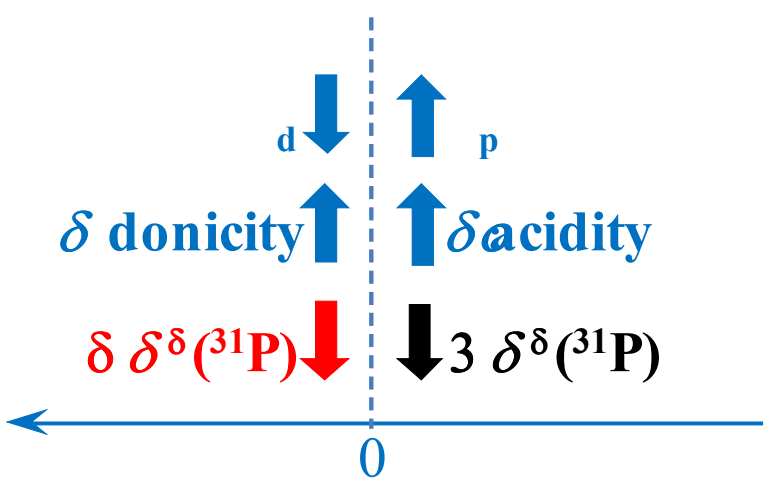

$$
\text { positive } \longleftarrow 3 \Pi\left(\Pi^{31} \mathrm{P}\right) \longrightarrow \text { negative }
$$

Regarding the correlation described by Equation 11, it is shown that the electronic parameters $\chi_{\mathrm{d}}$ and $E_{\mathrm{ar}}$, are equally important in determining the magnitude of ${ }^{1} J(\mathrm{Rh}-\mathrm{P})$, implying a dependence of the form (Equation 13 and Table 6):

$$
{ }^{1} J(\mathrm{Rh}-\mathrm{P})=\text { constant }+{ }^{1} J^{\sigma}(\mathrm{Rh}-\mathrm{P})+{ }^{1} \mathrm{~J} \text { ar }(\mathrm{Rh}-\mathrm{P})
$$


It is worth noting that the $\pi$-bonding ability of the phosphite ligands (expressed by $\pi_{\mathrm{p}}$ ) seems not to contribute to the magnitude of ${ }^{1} J(\mathrm{Rh}-\mathrm{P})$, which depends only on the $\sigma$-bonding ability (expressed by $\chi_{\mathrm{d}}$ ) and the "aryl effect" parameter $E_{\text {ar. }}$ The magnitude of ${ }^{1} J(\mathrm{Rh}-\mathrm{P})$ parallels weak, rather than strong, $\sigma$-donation, in accordance with published experimental observations. ${ }^{34}$

The aforementioned linear relation between ${ }^{1} J(\mathrm{Rh}-\mathrm{P})$ and $\chi_{\mathrm{d}}{ }^{34}$ is in agreement with equation 11 , since for all the phosphines studied the parameter $E_{\mathrm{ar}}=2.7$.

\section{CONCLUSION}

We have synthesized and studied new bimetallic TTMR complexes, in which the stabilization of $\mathrm{Rh}(\mathrm{I})$ is accomplished through the coordination of strong $\pi$-acceptors (2-8) and $\sigma$-donor diphosphines (9-11). The X-ray crystal structure of $\mathbf{2}$ has revealed that the Rh-Mo distance is indicative of bonding interactions and that the $\mathrm{Rh}(\mu-\mathrm{S})_{2}$ Mo ring is perfectly planar. The DFT study of complexes $\mathbf{2}, \mathbf{3}, \mathbf{4}, \mathbf{6}, \mathbf{7}$ and $\mathbf{8}$ has shown that there are five delocalized bonding MOs over the four-membered $\operatorname{Rh}(\mu-\mathrm{S})_{2} \mathrm{Mo}$ ring. These MOs contribute to the electronic communication between the metal centers. The electronic absorption spectra consist of a well resolved intense main band in the Vis region and two shoulders at lower wavelengths, so that they can be used as a diagnostic criterion for the confirmation of the formation of TTMR complexes. The TDDFT study of the electronic spectra showed that the main band is assigned to the $\mathrm{HOMO} \rightarrow$ LUMO transition, which is a $v(\mathrm{Rh} \rightarrow \mathrm{Mo})$ electron transfer transition.

It was shown that, for the complexes with phosphite ligands, the $v(\mathrm{Rh} \rightarrow \mathrm{Mo})$ correlates linearly with Tolman's electronic parameter, rendering $v(\mathrm{Rh} \rightarrow \mathrm{Mo})$ a well defined electronic parameter for monodentate and bidentate ligands. 
The examination of the correlations of $\Delta \delta(\mathrm{P})$ and ${ }^{1} J(\mathrm{Rh}-\mathrm{P})$ for complexes $\mathbf{4 - 8}$ with respect to the QALE model electronic parameters $\chi_{\mathrm{d}}, \pi_{\mathrm{p}}$ and $E_{\mathrm{ar}}$ has shown: (i) that both the $\sigma$ electron donor capacity and the $\pi$ electron acceptor capacity of the phosphites seem to be equally important in determining the sign and the magnitude of $\Delta \delta(\mathrm{P})$ and (ii) that ${ }^{1} J(\mathrm{Rh}-\mathrm{P})$ depends only on the $\sigma$-bonding ability and the "aryl effect" parameter.

\section{EXPERIMENTAL SECTION}

General Procedures. All operations were performed under a pure nitrogen atmosphere, using Schlenk and syringe techniques. $[\mathrm{RhCl}(\mathrm{COD})]_{2},{ }^{39}\left(\mathrm{NH}_{4}\right)_{2} \mathrm{MoS}_{4}$ and $\left(\mathrm{NEt}_{4}\right)_{2} \mathrm{MoS}_{4}{ }^{18}$ were prepared according to literature methods. $\left(\mathrm{PPh}_{4}\right)_{2} \mathrm{MoS}_{4}$ was obtained by metathetical reaction of the ammonium salt with $\mathrm{PPh}_{4} \mathrm{Br}$ in water. The phosphorus ligands used are commercially available and were stored under Ar. The purity of each ligand was estimated by measuring the ${ }^{31} \mathrm{P} N \mathrm{NR}$ before the synthetic experiments. All solvents were dried by standard methods and were degassed by bubbling nitrogen for $30 \mathrm{~min}$. ESI-MS measurements of acetonitrile solutions of the complexes were performed on a Thermo Scientific TSQ Quantum Access Triple Quadrupole Instrument. The measurements were performed in full scan mode and in negative ionization mode. The samples for the spectroscopic measurements were taken directly from the reaction mixtures and diluted with the appropriate solvent. The electronic absorption spectra were measured on a Varian Cary 3E UV/VIS Spectrophotometer. The ${ }^{31} \mathrm{P}$ NMR spectra were measured on a Varian Unity Plus 300 spectrometer and were referenced with an external standard of $\mathrm{H}_{3} \mathrm{PO}_{4} 85 \%$. 
Synthesis of 2(NEt ${ }_{4}^{+}$salt $) .[\mathrm{RhCl}(\mathrm{COD})]_{2}(0.0099 \mathrm{~g}, 0.02 \mathrm{mmol})$ was introduced in a Schlenk flask with acetone $(15 \mathrm{~mL})$ and was stirred for dissolution. In another Schlenk flask $\left(\mathrm{NEt}_{4}\right)_{2}\left[\mathrm{MoS}_{4}\right](0.0196 \mathrm{~g}, 0.04 \mathrm{mmol})$ was introduced with $\mathrm{CH}_{3} \mathrm{CN}(15 \mathrm{~mL})$ and was also stirred for dissolution. The tetrathiomolybdate solution was transferred by syringe equipped with a long thin needle and added dropwise to the stirred rhodium solution $(\sim 15 \mathrm{~min})$. The resulting solution was stirred for $20 \mathrm{~min}$ at room temperature and concentrated under vacuum $c a .2 \mathrm{~mL}$. Addition of $n$-hexane $(10 \mathrm{~mL})$ precipitated a pink solid and the precipitation was completed by standing at $-20^{\circ} \mathrm{C}$. The pink solid was collected by filtration, washed with $n$-hexane and dried under vacuum. (Yield $0.22 \mathrm{mg}, 96 \%$ ).

Anal. Calcd. for C16H32MoNRhS4: C, 33.87; H, 5.69; N, 2.47; S. 22.56. Found: C, 33.02; H, $5.54 ; \mathrm{N}, 2.62 ; \mathrm{S}, 22.40$.

HRMS: Exact $m / z$ calcd. for [(COD)Rh( $\left.\left(\mathrm{MoS}_{4}\right)\right]^{-} 436.79309$; found: 436.70 .

Syntheses of 4-11 ( $\mathbf{N E t}_{4}{ }^{+}$salts). In a typical reaction, $[\mathrm{RhCl}(\mathrm{COD})]_{2}(0.0099 \mathrm{~g}, 0.02 \mathrm{mmol})$ was introduced in a Schlenk tube with acetone $(15 \mathrm{~mL})$ and was stirred for dissolution. In another Schlenk tube $\left(\mathrm{NEt}_{4}\right)_{2}\left[\mathrm{MoS}_{4}\right](0.0196 \mathrm{~g}, 0.04 \mathrm{mmol})$ was introduced with $\mathrm{CH}_{3} \mathrm{CN}$ $(15 \mathrm{~mL})$ and was also stirred for dissolution. The tetrathiomolybdate solution was transferred by syringe equipped with a long thin needle and added dropwise to the stirred rhodium solution ( $\sim 15 \mathrm{~min})$. The resulting solution was stirred for $20 \mathrm{~min}$ and the stoichiometric quantity of the $\mathrm{P}(\mathrm{III})$ ligand ( $0.08 \mathrm{mmol}$ of phosphite or $0.04 \mathrm{mmol}$ of diphosphine) was added. The color of the reaction mixture changed rapidly, indicative the formation of the product. The reaction mixture was stirred for $1 \mathrm{~h}$. Addition of $n$-hexane $(10 \mathrm{~mL})$ precipitated the solid product and the 
precipitation was completed by standing at $-20^{\circ} \mathrm{C}$. The product was collected by filtration, washed with $n$-hexane and dried under vacuum.

HRMS for complexes 4-11 $\left(\mathrm{NEt}_{4}{ }^{+}\right.$salts):

4 (red-orange): Exact $m / z$ calcd. for $\left[\left(\left(\mathrm{P}(\mathrm{OPh})_{3}\right)_{2} \mathrm{Rh}\left(\mathrm{MoS}_{4}\right)\right]^{-}: 948.85095\right.$; found: 948.03 .

5 (red-orange): Exact $m / z$ calcd. for $\left[\left(\left(\mathrm{P}(\mathrm{O}-o-\mathrm{Tol})_{3}\right)_{2} \mathrm{Rh}\left(\mathrm{MoS}_{4}\right)\right]^{-}: 1032.94486\right.$; found: 1032.89 .

6 (dark-red): Exact $m / z$ calcd. for $\left[\left(\left(\mathrm{P}(\mathrm{OMe})_{3}\right)_{2} \mathrm{Rh}\left(\mathrm{MoS}_{4}\right)\right]^{-}: 576.75705\right.$; found: 574.36 .

7 (violet-red): Exact $m / z$ calcd. for $\left[\left(\left(\mathrm{P}(\mathrm{OEt})_{3}\right)_{2} \mathrm{Rh}\left(\mathrm{MoS}_{4}\right)\right]^{-}: 660.85095\right.$; found: 658.21.

8 (red-violet): Exact $m / z$ calcd. for $\left[\left(\left(\mathrm{P}(\mathrm{O}-i-\mathrm{Pr})_{3}\right)_{2} \mathrm{Rh}\left(\mathrm{MoS}_{4}\right)\right]^{-}: 744.94485\right.$; found: 744.32 .

9 (dark-red): Exact $m / z$ calcd. for [(cis-dppen)Rh( $\left.\left.\mathrm{MoS}_{4}\right)\right]=724.81886$; found: 723.14 .

10 (light-violet): Exact $m / z$ calcd. for [(dppe)Rh(MoS 4$)]^{-}: 726.8354$; found: 726.86.

11 (violet): Exact $m / z$ calcd. for $\left[(\mathrm{dppb}) \mathrm{Rh}\left(\mathrm{MoS}_{4}\right)\right]^{-}:$754.8658; found: 754.34 .

Reaction of 2 with $\boldsymbol{C O}$. A freshly prepared solution of $\mathbf{2}$ in acetone was purged, cautiously and at very low rate, with $\mathrm{CO}(\sim 10 \mathrm{~s})$ until the red orange solution turned to yellow (Caution: fume hood). The carbonylation reaction can be also performed in acetonitrile or dichloromethane. The solution of the dicarbonyl derivative is fairly stable, at least enough for the measurement of the IR spectrum.

Prolonged bubbling of $\mathrm{CO}$ results in the change of the color of the solution to dark golden. This indicates the collapse of the yellow dicarbonyl cluster, 3 .

X-ray Crystal Structure Determination. X-ray diffraction measurements were made using a Bruker SMART CCD area-detector diffractometer with Mo Ka radiation $(\mathrm{k}=0.71073 \mathrm{E}){ }^{40}$ Single crystals of $\mathrm{C}_{16} \mathrm{H}_{32} \mathrm{NS}_{4} \mathrm{MoRh}$ were obtained by slow diffusion of $n$-hexane into a solution 
of the complex in dichloromethane. A suitable crystal was selected and was mounted in glass fiber on the diffractometer. The crystal was kept at 301(2) K during data collection. Using Olex $2,{ }^{41}$ the structure was solved with the ShelXT ${ }^{42}$ structure solution program using Direct Methods and refined with the ShelXL ${ }^{42}$ refinement package using Least Squares minimisation. CCDC-660513 contains the supplementary crystallographic data for compound $\left(\mathrm{NEt}_{4}\right)\left[(\mathrm{COD}) \mathrm{Rh}\left(\mathrm{MoS}_{4}\right)\right]$. The data can be obtained free of charge from The Cambridge Crystallographic Data Centre via www.ccdc.cam.ac.uk/data_request/cif.

Computational Methods / Details. All calculations were done with the Gaussian 09 suite of programs. $^{44}$ The SVP basis is a split-valence plus polarization ${ }^{45}$ and the TZVPP is a triple zeta valence plus double polarization including an effective core potential. ${ }^{46,47}$ In some cases geometry optimizations were first performed at the SVP level, followed by full optimization with the TZVPP basis. This reduces the computational costs significantly. The popular B3LYP functional is due to Becke ${ }^{48}$ and Lee, Yang and Parr $^{49}$ and contains empirical data. The TZVPP computations were made faster using the Density Fitting approximation. ${ }^{50}$ The structures were fully optimized and stationary points characterized by second derivative calculations to confirm that they are true minima. 


\section{ASSOCIATED CONTENT}

Supporting Information. List of rhodium tetrathiometallato complexes; ESI-MS of TTMR complexes; $\left(\mathrm{NEt}_{4}\right)\left[\left(\eta^{4}-\mathrm{cod}\right) \mathrm{Rh}(\mu-\mathrm{S})_{2} \mathrm{MoS}_{2}\right]$ X-ray crystal structure (crystal data and structure refinement); optimized structures of complexes $\mathbf{2 , 3 , 4 , 6 , 7 , 8}$; HOMO and LUMO of complexes $\mathbf{2 , 3 , 4 , 6 , 7 , 8}$; QALE electronic parameters for $\mathrm{P}(\mathrm{O}-\mathrm{o}-\mathrm{Tol})_{3}$; statistical analysis of the QALE multiple regressions. This material is available free of charge via the Internet at http://pubs.acs.org.

\section{AUTHOR INFORMATION}

\section{Corresponding Authors}

*E-mail: koinis@chem.uoa.gr. Phone: +30-210-72-74-458. Fax: +30-210-72-74-782.

*E-mail: msim@eie.gr Phone: +30-210-72-73-806. Fax: +30-210-72-73-794.

\section{Author Contributions}

The manuscript was written through contributions of all authors. All authors have given approval to the final version of the manuscript.

\section{ACKNOWLEDGMENT}

S.K. is grateful to Prof. Pablo Espinet for the availability of the X-ray diffractometer and to Prof. N. Thomaidis for the availability of the mass spectrometer. 


\section{REFERENCES}

1. (a) Diemann, E.; Müller, A. Coord. Chem. Rev. 1973, 10, 79-122. (b) Müller, A.; Diemann, E.; Jostes, R.; Bögge, H. Angew. Chem. Int. Ed. Engl. 1981, 20, 934-955. (c) Coucouvanis, D. Acc. Chem. Res. 1981, 14, 201-209. (d) Müller, A.; Diemann, E. Comprehensive Coordination Chemistry (Eds.: G. Wilkinson, R. D. Gillard, J. A. McCleverty), Pergamon Press, Oxford, 1987, vol. 2, 559-577. (e) Coucouvanis, D. Adv. Inorg. Chem. 1998, 45, 1-73. (f) Laurie, S. H. Eur. J. Inorg. Chem. 2000, 2443-2450. (g) Niu, Y; Zheng, H.; Hou, H.; Xin, X. Coord. Chem. Rev. 2004, 248, 169-183. (h) Rauchfuss, T. Inorg. Chem. 2004, 43, 14-26.

2. (a) Coucouvanis, D. Acc. Chem. Res. 1991, 24, 1-8. (b) Lee, S. C.; Holm, R. H. Chem. Rev. 2004, 104, 1135-1157.

3. (a) Brenner, J. R.; Marshall, C. L.; Nieman, G. C.; Parks, E. K.; Riley, S. J.; Ellis, L.; Tomczyk, N. A.; Winans, R. E. J. Catal. 1997, 166, 294-305. (b) Walton, R. I.; Dent, A. J.; Hibble, S. J. Chem. Mater. 1998, 10, 3737-3745. (c) R. Huirache-Acuña, R.; Albiter, M. A.; Espino, J.; Ornelas, C.; Alonso-Nuñez, G.; Paraguay-Delgado, F.; Rico, J. L.; Martínez-Sánchez, R. Appl. Catal. A 2006, 304, 124-130. (d) Huiracho-Acuña, R.; Alonso-Núñez, G.; ParaguayDelgado, F.; Lara-Romero, J.; Berhault, G.; Rivera-Muñoz, E. M. Catal. Today 2015, 250, 28 37.

4. Zhang, J.; Meng, C.; Song, Y.; Zhao, H., Li, J.; Qu, G.; Sun, L.; Humphrey, M. J.; Zhang, C. Chem. Eur. J. 2010, 16, 13946-13950 and references therein.

5. (a) Howard, K. E.; Rauchfuss, T. B.; Wilson S. R. Inorg. Chem. 1988, 27, 3561-3567. (b) Polychronopoulou, K.; Malliakas, C. C.; He, J.; Kanatzidis, M. G. Chem. Mater. 2012, 24, 33803392.

6. (a) Tanaka, K.; Morimoto, M.; Tanaka, T. Inorg. Chim. Acta 1981, 56, L61-L63. (b) Laughlin, L. J.; Coucouvanis, D. J. Am. Chem. Soc. 1995, 117, 3138-3125. (c) Coucouvanis, D.; Demadis, K. D.; Malinak, S. M.; Mosier, P. E.; Tyson, M. A.; Laughlin, L. J. J. Mol. Catal. A: Chem. 1996, 107, 123-135. (d) Graca-Mora, J.; Diaz, D. Transition Met. Chem. 1998, 23, 57-61. (e) Shafaei-Fallah, M.; Malliakas, C. D.; Kanatzidis, M. G. Z. Anorg. Allg. Chem. 2012, 638, 25942597.

7. (a) Brewer, G. J. Semin. Integr. Med. 2003, 1, 181-190. (b) Quagraine, E. K.; Georgakaki, I.; Coucouvanis, D. J. Inorg. Biochem. 2009, 103 143-155 and references therein.

8. Howard, K. E.; Rauchfuss, T, B.; Rheingold, A. L. J. Am. Chem. Soc. 1986, 108, 297-299.

9. Harmer, M. A.; Sykes, A. G. Inorg. Chem. 1980, 19, 2881-2885.

10. (a) Tieckelmann, R. H.; Silvis, H. C.; Kent, T. A.; Huynh, B. H.; Waszezak, J. V.; Teo, B.K.; Averill, B. A. J. Am. Chem. Soc. 1980, 102, 5550-5559. (b) Coucouvanis, D.; Stremple, P.; Simhon, E. D.; Swenson, D.; Baenziger, N. C.; Draganjac, M.; Chan, L. T.; Simopoulos, A.; Papaefthymiou, V.; Kostikas, A.; Petrouleas, V. Inorg. Chem. 1983, 22, 293-308. (c) Gheller, S. F.; Hambley, T. W.; Rodgers, J. R.; Brownlee, R. T. C.; O'Connor, M. J.; Snow, M. R.; Wedd, 
A. G. Inorg. Chem. 1984, 23, 2519-2528. (d) Müller, A.; Bögge, H.; Schimanski, U.; Penk, M.; Nieradzik, K.; Dartmann, M.; Krickemeyer, E.; Schimanski, J.; Römer, C.; Römer, M.; Dornfeld, H.; Wienböker, U.; Hellmann, W.; Zimmermann, M. Monatsh. Chem. 1989, 120, 367-391. (e) Zheng, H. G; Tan, W.; Jin, G.; Ji, W.; Jin, Q.; Huang, X.; Xin, X. Q. Inorg. Chim. Acta 2000, 305, 14-18.

11. (a) Siedle, A. R.; Gleason, W. B. Inorg. Chem. 1986, 25, 4054-4057. (b) Toohey, M. J.; Scattergood, C. D.; Garner, C. D. Inorg. Chim. Acta 1987, 129, L19. (c) Howard, K. E.; Rauchfuss, T, B.; Wilson S. R. Inorg. Chem. 1988, 27, 1710-1716. (d) Howard, K. E.; Rauchfuss, T, B.; Wilson S. R. Inorg. Chem. 1988, 27, 3561-3567. (e) Ruiz, J.; Rodríguez, V.; López, G.; Chaloner, P. A.; Hitchcock, P. B. J. Organomet. Chem. 1995, 493, 77-82.

12. Coucouvanis, D.; Simhon, E. D.; Baenziger, N. C. J. Am. Chem. Soc. 1980, 102, 6644-6646.

13. (a) Bernholc, J.; Stiefel, E. I. Inorg. Chem. 1985, 24, 1623-1330. (b) Jostes, R.; Müller, A.; Diemman, E. THEOCHEM 1986, 137, 311-328. (c) Chunwan, L,; Jianmin, H.; Zhida, C.; Zhenyang, L.; Jiaxi, L. Int. J. Quantum Chem. 1986, 29, 701-715. (d) Bownmaker, G. A.; Boyd, P. D. W.; Sorrenson, R. J.; Reed, C. A.; McDonald, J. W. Inorg. Chem. 1987, 26, 3-9. (e) El-Issa, B. D.; Zeedan, M. M. Inorg. Chem. 1991, 30, 2594-2605. (f) Chan, C.-K.; Guo, C.-X.; Wang, R.J.; Mak, T. C. W.; Che, C.-M. J. Chem. Soc. Dalton Trans. 1995, 753-757. (g) Zli, S.; Stoll, H.; Baerends, E. J.; Kaim, W. Inorg. Chem. 1999, 38, 6101-6105. (h) Gill, P.; Tsipis, A. C. Int. J. Quantum. Chem. 2007, 107, 418-439. (f) Zhang, J.; Meng, S.; Song, Y.; Zhao, H.; Li, J.; Qu, G.; Sun, L.; Humphrey, Zhang, C. Chem. Eur. J. 2010, 16, 13946-13950.

14. Seino, H.; Mizobe, Y.; Hidai, M. Bull. Chem. Soc. Jpn. 2000, 73, 631-639.

15. (a) Ogo, S.; Suzuki, T.; Nomura, S; Asakura, K.; Isobe, K. J. Clust. Sci. 1995, 6, 421-436. (b) Ogo, S.; Suzuki, T.; Ozawa, Y.; Isobe, K. Chem. Lett. 1994, 1235; Inorg. Chem. 1996, 35, 60936101. (c) Wanner, M.; Hartenbach, I.; Fiedler J.; Schleid, Th.; Kaim W. Z. Naturforsch. 2001, 56b, 940-946. (d) Herberhold, M.; Jin, G.-X.; Rheingold, A. L. Z. Anorg. Allg. Chem., 2005, 631, 135-140.

16. (a) Van Leeuwen, P. W. N. M.; Claver, C. in Rhodium-catalyzed Hydroformylation, Kluwer, Dordrecht, 2000. (b) Evans, P. A. in Modern Rhodium-catalyzed Organic Reactions, WileyVCH, Weinheim, 2005.

17. Liakakos, N.; Cormary, B.; Li, X.; Lecante, P.; Respaud, M.; Maron, L.; Falqui, A.; Genovese, A.; Vendier, L.; Koinis, S.; Chaudret, B.; Soulantica, K. J. Am. Chem. Soc., 2012, 134, 17922-17931.

18. McDonald, J. W.; Friesen, G. D.; Rosenhein, L. D.; Newton, W. E. Inorg. Chim. Acta 1983, $72,205-210$.

19. (a) Vallarino, L. M. Inorg. Chem. 1965, 4, 161-165. (b) T.P.Dougherty, W.T.Grubbs, E.J.Hellwell, J.Phys.Chem. 1994, 98, 9396-9399.

20. (a) Tolman, C. A. J. Am. Chem. Soc. 1970, 92, 2953-2956; (b) Tolman, C. A. Chem. Rev. 1977, 77, 313. 
21. Cotton, F. A.; Li, Z.; Liu, C. Y.; Murillo, C. A. Inorg. Chem. 2007, 46, 9294-9302.

22. Alyea, E. C.; Song, S. Inorg. Chem. 1995, 34, 3864-3873.

23. Kühl, O. Phosphorus-31 NMR Spectroscopy; Springer-Verlag; Berlin-Heidelberg, 2008.

24. (a) Dias, P. D.; de Piedade, M. E. M.; Marinho Simões, J. A. Coord. Chem. Rev. 1994, 135/136, 737-807. (b) Kühl, O. Coord. Chem. Rev. 2005, 249, 693-704.

25. Bartik, T.; Himmler, T.; Schulte, H.-G.; Seevogel, K. J. Organomet. Chem. 1984, 272, 29-41.

26. (a) Perrin, L.; Clot, E.; Eisenstein, O.; Loch, J.; Crabtree, R. H. Inorg. Chem. 2001, 40, 58065811. (b) Kalescky, R.; Kraka, E.; Cremer, D. Inorg. Chem. 2014, 53, 478-495 and references 526 therein.

27. Gusev, D. G.; Peris, E. Dalton Trans. 2013, 42, 7359-7364.

28. Anton, D. R.; Crabtree, R. H. Organometallics 1983, 2, 621-627.

29. Cotton, F. A.; Edwards, W. T.; Rauch, F. C.; Graham, M. A.; Perutz, R. N.; Turner, J. J. J. Coord. Chem. 1973, 2, 247-250.

30. Meriwether, L. S.; Leto, J. R. J. Am. Chem. Soc. 1961, 83, 3192-3196.

31. Ruiz-Morales, Y.; Ziegler, T. J. Phys. Chem. A 1998, 102, 3970-3976.

32. Mathieu, R.; Lenzi, M.; Poilblanc, R. Inorg. Chem. 1970, 9, 2030-2034.

33. (a) Pregosin, P. S.; Kunz, R. W. ${ }^{31} P$ and ${ }^{13} C$ NMR of Transition Metal Phosphine Complexes; Springer-Verlag: Berlin, 1979. (b) Song, S.; Alyea, E. C. Comments Inorg. Chem. 1996, 18, 145164.

34. Tiburcio, J.; Bernès, S.; Torrens, H. Polyhedron 2006, 25, 1549-1554.

35. Pidcock, A.; Richards, R. E.; Venanzi, L. M. J. Chem. Soc. A 1996, 1707-1710.

36. (a) Rahman, M.M.; Liu, H.-Y.; Prock, A.; Giering, W. P. Organometallics 1987, 6, 650-658. (b) Rahman, M.M.; Liu, H.-Y.; Eriks, K.; Prock, A.; Giering, W. P. Organometallics 1989, 8, 1 7. (c) Eriks, K.; Giering, W. P.; Liu, H.-Y.; Prock, A. Inorg. Chem. 1989, 28, 1759-1763. (d) Liu, H.-Y.; Eriks, K.; Prock, A.; Giering, W. P. Organometallics 1990, 9, 1758-1766. (e) Wilson, M. R.; Woska, D. C.; Prock, A.; Giering, W. P. Organometallics 1993, 12, 1742-1752. (f) Fernandez, A. L.; Prock, A.; Giering, W. P. Organometallics 1994, 13, 2767-2772. (g) Lorsbach, B. A.; Bennett, D. M.; Prock, A.; Giering, W. P. Organometallics 1995, 14, 869-874. (h) Lorsbach, B. A.; Prock, A.; Giering, W. P. Organometallics 1995, 14, 1694-1699. (i) Fernandez, A. L.; Prock, A.; Giering, W. P. Organometallics 1996, 15, 2784-2789. (j) Woska, D.; Prock, A.; Giering, W. P. Organometallics 2000, 19, 4629-4638. (k) Fernandez, A. L.; Reyes, C.; Prock, A.; Giering, W. P. J. Chem. Soc., Perkin Trans. 2 2000, 1033-1041. (1) Wilson, M. R.; Prock, A.; Giering, W. P.; Fernandez, A. L.; Haar, C. M.; Nolan, S. P.; Foxman, B. M. Organometallics 2002, 21, 2758-2763.

37. Tolman, C. E. J. Am. Chem. Soc. 1970, 92, 2956-2965. 
38. Tolman, C. A.; Seidel, W. C.; Gosser, L. W. J. Am. Chem. Soc. 1974, 96, 53-60.

39. Giordano, G.; Crabtree, R. H. Inorg. Synth. 1990, 28, 88-90.

40. SMART V5.051 Diffractometer Control Software, Bruker Analytical X-ray Instruments Inc., Madison, WI (1998).

41. Dolomanov, O. V.; Bourhis, L. J.; Gildea, R. J.; Howard, J. A. K.; Puschmann, HJ. Appl.

Cryst. 2009, 42, 339-341.

42. Sheldrick, G.M. Acta Cryst. 2015, A71, 3-8.

43. Sheldrick, G.M. (2015). Acta Cryst. 2015, C71, 3-8.

44. G. W. T. M. J. Frisch, H. B. Schlegel, G. E. Scuseria, M. A. Robb, J. R. Cheeseman, G. Scalmani, V. Barone, B. Mennucci, G. A. Petersson, H. Nakatsuji, M. Caricato, X. Li, H. P. Hratchian, A. F.Izmaylov, J. Bloino, G. Zheng, J. L. Sonnenberg, M. Hada, M. Ehara, K. Toyota, R. Fukuda, J. Hasegawa, M. Ishida, T. Nakajima, Y. Honda, O. Kitao, H. Nakai, T. Vreven, J. A. Montgomery Jr., J. E. Peralta, F. Ogliaro, M. Bearpark, J. J. Heyd, E. Brothers, K. N. Kudin, V. N. Staroverov, R. Kobayashi, J. Normand, K. Raghavachari, A. Rendell, J. C. Burant, S. S. Iyengar, J. Tomasi, M. Cossi, N. Rega, J. M. Millam, M. Klene, J. E. Knox, J. B. Cross, V. Bakken, C. Adamo, J. Jaramillo, R. Gomperts, R. E. Stratmann, O. Yazyev, A. J. Austin, R. Cammi, C. Pomelli, J. W. Ochterski, R. L. Martin, K. Morokuma, V. G. Zakrzewski, G. A. Voth, P. Salvador, J. J. Dannenberg, S. Dapprich, A. D. Daniels, Ö. Farkas, J. B. Foresman, J. V. Ortiz, J. Cioslowski, and D. J. Fox, Gaussian 09, Revision A.1 (2009), Gaussian, Inc., Wallingford CT.

45. Ahlrichs, R.; May, K. Phys. Chem. Chem. Phys. 2000, 2, 943-945.

46. Weigend, F.; Ahlrichs, R. Phys. Chem. Chem. Phys. 2005, 7, 3297-3305.

47. Andrae, D.; Haussermann, U.; Dolg, Stoll, M. H.; Preuss, H. Theor. $\quad$ Chim. Acta 1990, 77, 123-141.

48. Becke, A. D. Phys. Rev. A 1988, 38, 3098-3100.

49. Lee, C. T.; Yang, W. T.; Parr, R. G. Phys. Rev. B 1988, 37, 785-789.

50. B. I. Dunlap, THEOCHEM 2000, 529, 37-40. 
Table of Contents Graphic and Synopsis

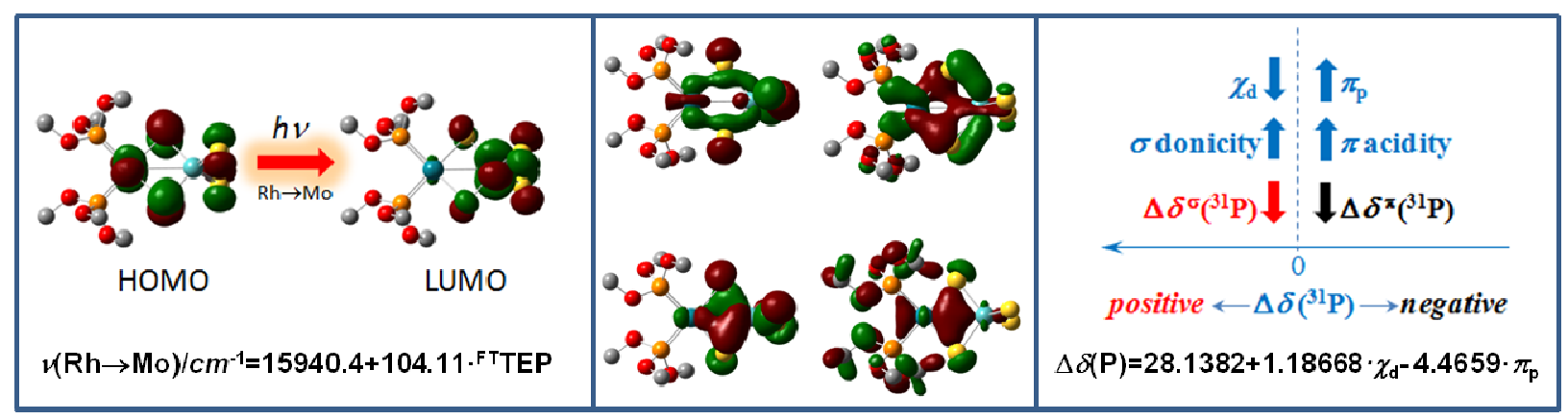

We report the synthesis, spectroscopy and DFT study of dinuclear tetrathiomolybdatorhodium(I) monoanionic complexes $\left[\mathrm{L}_{2} \mathrm{Rh}(\mu-\mathrm{S})_{2} \mathrm{MoS}_{2}\right]^{-}$. The examination of the bonding MOs show that there exists an extended electron delocalization over the four-membered $\mathrm{Rh}(\mu \text {-S })_{2} \mathrm{Mo}$ ring, and hence the possibility of electronic communication between the metal centers. Finally it is shown that both the electronic and the ${ }^{31} \mathrm{P}$ NMR spectra of the complexes with phosphite ligands are predictable in terms of widely used ligand electronic parameters, Tolman's and QALE electronic parameters, respectively. 
We report the synthesis, spectroscopy and DFT study of dinuclear tetrathiomolybdatorhodium(I) monoanionic complexes [L2Rh(mu-S)2MoS2]-. The examination of the bonding MOs show that there exists an extended electron delocalization over the four-membered $\mathrm{Rh}(\mathrm{mu}-\mathrm{S}) 2 \mathrm{Mo}$ ring, and hence the possibility of electronic communication between the metal centers. Finally it is shown that both the electronic and the 31P NMR spectra of the complexes with phosphite ligands are predictable in terms of widely used ligand electronic parameters, Tolman's and QALE electronic parameters, respectively. 